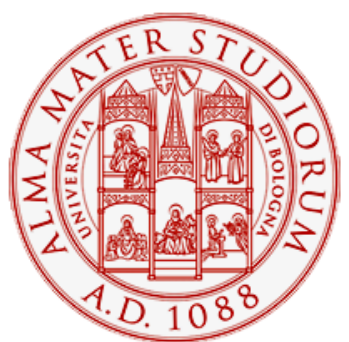

Alma Mater Studiorum - Università di Bologna DEPARTMENT OF ECONOMICS

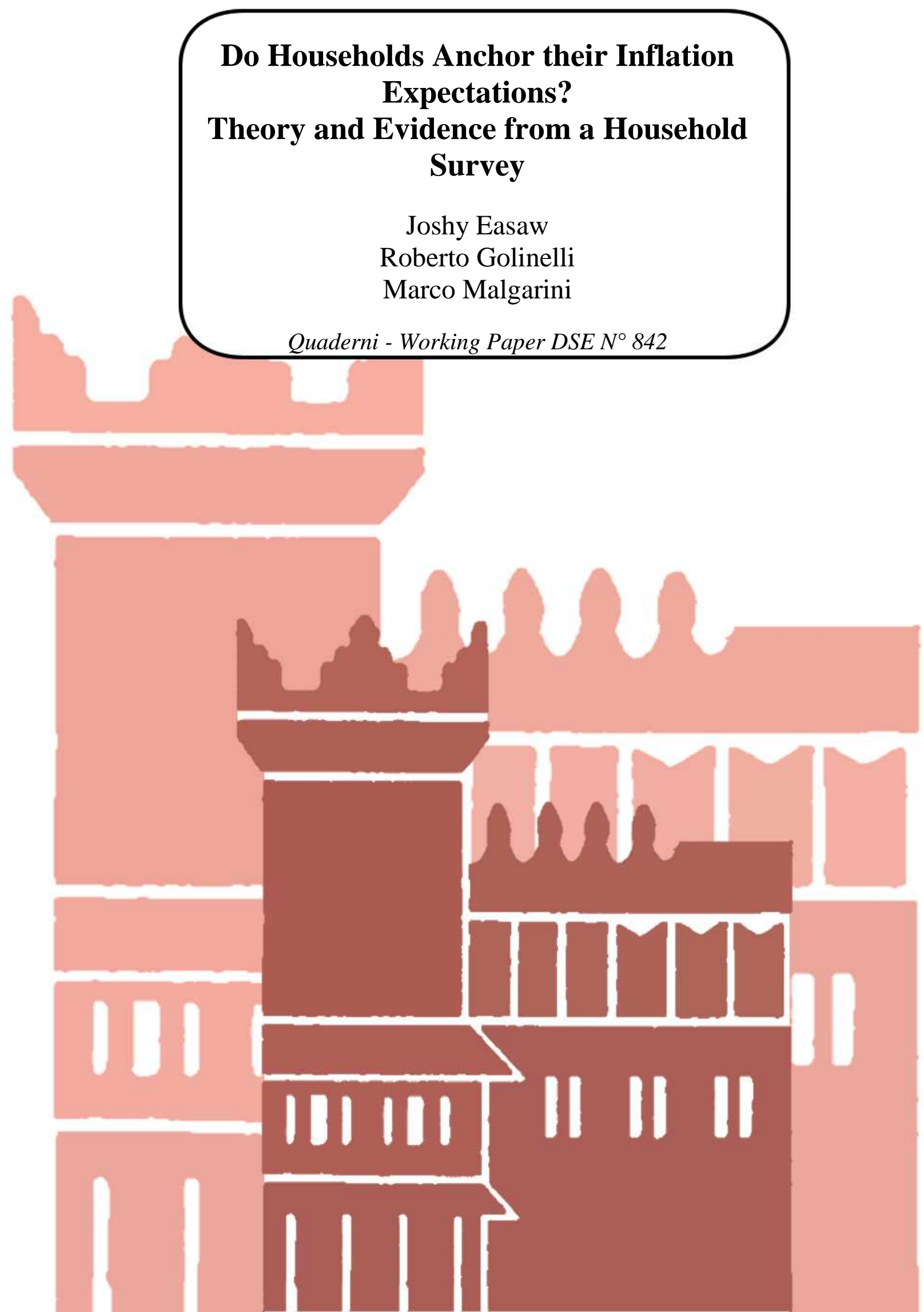




\title{
Do Households Anchor their Inflation Expectations? Theory and Evidence from a Household Survey ${ }^{1}$
}

\author{
Joshy Easaw $^{\mathrm{a}}$, Roberto Golinelli ${ }^{\mathrm{b}}$ and Marco Malgarini ${ }^{\mathrm{c}}$
}

$\left({ }^{a}\right)$ School of Business and Economics, University of Swansea, Singleton Park, Swansea, SA2 8PP, United Kingdom; J.Easaw@swansea.ac.uk

( b) Department of Economics, University of Bologna, Strada Maggiore 45, 40125 Bologna, Italy; roberto.golinelli@unibo.it

(c) National Agency for the Evaluation of Universities and Research Institutes (ANVUR); malgmarco@gmail.com

August 2012

\footnotetext{
$1 \quad$ An earlier version of the paper was presented at: the Centre for Applied Macroeconomic Analysis, ANU, Canberra, May, 2010, at the 30th CIRET Conference, New York, October 2010, at the EU Workshop on Recent Developments in Business and Consumer Surveys, Brussels, at the Federal Reserve Bank of New York conference on 'Consumer Inflation Expectations', New York, NY, November, 2010, at the fourth Italian Congress of Econometrics and Empirical Economics (ICEEE), Pisa, Italy, January,, 2011 and at the Institute Brasileiro de Economia (IBRE), Fundação Getulio Vargas, Rio de Janeiro, Brasil, April, 2011. We also gratefully acknowledge the comments and suggestions of Jan Mark Berk, John Lewis, Shaun Vahey and the conference and workshop participants. The usual disclaimer applies. PRIN financing is gratefully acknowledged (R. Golinelli). The views expressed in this paper are those of the authors and do not involve the responsibility of the institutions they belong.
} 


\title{
Do Households Anchor their Inflation Expectations? \\ Theory and Evidence from a Household Survey
}

\begin{abstract}
.
The purpose of the present paper is to study how households form inflation expectations. Using a novel survey-base dataset of Italian households' opinions of inflation we investigate two separate, but related, types of behavior: 'inattentiveness' and 'anchoring'. The present analysis extends the existing literature by incorporating explicitly inflation targets and distinguishing between aggregate and disaggregate dynamics based on demographic groups. In addition, we extend the literature by considering both the short- and long-run dynamics as households update their inflation expectations while also accounting for their state-varying behavior. All these issues provide important insights into understanding actual inflation dynamics and the conduct of monetary policy.
\end{abstract}

Keywords: Inflation expectations, perceived inflation, survey data, heterogeneous panels, nonlinear effects.

JEL classification: $\quad$ D1, D84, E1, E31, C33 


\section{Introduction}

Most models explaining aggregate outcomes, such as business cycles and inflation dynamics, include households' (or non-expert) expectations. Nevertheless, how households form their expectations about the macroeconomy is less well studied or understood. Two separate but related research have emerged recently to give important insights into the issue: 'rational inattentive' behavior and the 'anchoring' behavior of agent's expectations with inflation targeting and central bank independence.

The purpose of the present paper is to study how households form their inflation expectations - bringing together the main issues highlighted in this related research. The simple questions we ask are: To whom do households anchor when forming their inflation expectations? Do they anchor on the professional forecasts or on the Central Bank's targets and, are these anchors mutually exclusive? The purpose is to consider the key features of these two important developments explaining how households may form their inflation expectations. In many respects, they are competing models and we wish to determine which behavior dominates.

The underlying premise of the present analysis is also the one that motivates rational inattentive behavior, that is, the cost of acquiring relevant information. In a recent paper Coibion and Gorodnichenko (2010) suggested that central bank independence and explicit inflation targeting would reduce agents' inattentiveness. The least costly option for a household would be to anchor expectations on the Central Bank's target. However, this could also be the most costly option if these targets are not credible. While observing the professional forecasts and ascertaining the most recent actual inflation figures id costly, it may be worthwhile if the inflation targets set by monetary authorities lack credibility. Furthermore, for the general public to anchor on the professional forecast due to ignorance of the inflation target is not credible as it would be more costly to observe the former. The fact that professionals may anchor on an inflation target is coincidental - and the public would be unaware of this. Finally, it would be illogical for the public to acquire an inflation target via professional forecasts because it would be too costly. Nevertheless, we do not discount the fact that the public (or a proportion of the public) may look to anchor on both. During periods of macroeconomic uncertainty, they may look to both the inflation targets and professional forecasts. 
The paper investigates these issues using a novel survey-base dataset of households' opinions of inflation, which is compiled on a monthly basis from February 2003 for Italy and within the framework of the harmonized project of the European Commission. The initial empirical analysis follows the aggregate approach of the 'sticky information expectations' literature. Subsequently, we extend the analysis, accounting for individual household characteristics, using a pseudo-panel approach. Using a novel survey-based dataset allows us to investigate household behavior at disaggregate level distinguishing between various demographic groups.

A number of recent influential papers have introduced the notion of 'rational inattentive' behavior to explain how non-experts form expectations of the macroeconomy. Specifically, Reis (2006a; 2006b) argue that both consumers and producers update their information set sporadically. Producers do not continuously update their production plans but choose a price for their output and an optimal time at which to be inattentive, that is they receive no news about the economy until it is time to plan again. Similarly, time-constrained consumers optimize their utility and undertake consumption decisions infrequently. The slow diffusion of information among the general population is due to the costs of acquiring information as well as the costs of reoptimization. Such 'sticky information' expectations has been used to explain not only inflation dynamics (Mankiw and Reis, 2002) but also aggregate outcomes in general (Mankiw and Reis, 2007) and the implications for monetary policy (Ball et al., 2005).

Recently, Carroll (2003; 2006) put forward a specific form of 'sticky information' expectations that best explains how households form their expectations about the macroeconomy. 'Epidemiological expectations' argue that households form their expectations by observing professional forecasts which are reported in the news media. They, however, observe the professional forecasts imperfectly by 'absorbing' over time and, eventually, the professional forecasts are transmitted throughout the entire population. This proposition is verified empirically using a US household-based survey (Michigan SRC) and the Survey of Professional Forecasters (SPF). Lanne et al. (2009) considered an interesting extension of Carroll's epidemiological model. They showed empirically that a hybrid version of the sticky information model explains how households form their expectations; partly forming their expectations naïvely on recently released inflation rates and partly on professional forecasts. When analyzing households and non-experts in general it is useful not to consider them homogeneously. 
Indeed, Bryan and Venkatu (2001a; 2001b) focused on demographic differences (specifically gender differences) when investigating households forming inflation expectations and perceptions. It is also important to highlight at this stage that recently the notion and study of 'inattentiveness' have also been extended to professional forecasters and financial market experts (see Andrade and Le Bihan, 2010; and Coibion and Gorodnichenko, 2010).

An important and closely related development has been to analyze whether households' inflation expectations are 'anchored' on the inflation targets set by central banks (see for example, Levin et al., 2004; Kelly, 2008; Blanchflower \& Mac Coille, 2009; Gefang et al (2012) and references therein). Beechy et al. (2011), an important recent contribution to this literature, focuses on the anchoring behavior of experts' (or professionals') inflation expectations. This literature also considers the issue of monetary policy credibility. By and large these studies concentrating on professional forecasters and the financial market experts have focused on long-run forecasting horizons between three to five-years ahead forecasts. Nevertheless, recently Coibion and Gorodnichencko (2010) studying the forecasting behavior of both professional forecasters and households used short-run forecasting horizons of between six to twelve-months ahead forecasts. Also, Dovern et al (2012) studying the 'anchoring' behavior of professional forecasters by investigating the level of disagreements amongst their forecasts have used one-year ahead forecasts. When studying how households form macroeconomic expectation in general (and also specifically their 'anchoring' behavior) one is not only constrained by the lack of availability of long-term forecasting horizons data but also its appropriateness; Carroll (2003 and 2006) has argued that households are not able to distinguish the differences between forecasts for different horizons and, hence, these forecasts may be highly correlated.

The present empirical results clearly indicate that households anchor their expectations on professional forecasts. We also find that households are excessively sensitive to current inflation (or perceptions of current inflation) when forming their expectations. The estimated inflation expectations of all households are also considerably higher than the European Central Bank (ECB) targets for the period, despite their anchoring on professional forecasts, which approximates the inflation targets. These results are consistent with the findings of Coibion and Gorodnichencko (2010) and Dovern et al (2012) who find little evidence of inflation-targeting effecting expectations formation. In addition, households' inflation expectations tend to be lower 
with education (the university-educated having the lowest). Similarly, the absorption rates increase with education. There are also clear differences in behavior between male and females for all categories of households considered.

Our analysis further considers the role of current inflation when households form their expectations. We find that current signals are used to determine the future direction of inflation rates, and households respond to them asymmetrically. In fact, the non-linear absorption rates of all households increase considerably when they expect future inflation rates to rise. Our investigations also consider another interesting aspect of households' absorption rates: we test whether households overreact when they initially receive professional forecasts. When agents absorb or update their 'anchored' expectations imperfectly or update their information sporadically, one cannot rule out that they may overreact in the short run to new information. In most cases they may choose to update their expectations during periods of macroeconomic uncertainty or volatility and may simply be reflecting this.

The present paper contributes to existing literature and debates as follows: firstly, it studies the important issue of 'inattentiveness' and 'anchoring' focusing on households' using a novel dataset which covers the period of explicit inflation targeting by the European Central Bank (ECB). Similar to some recent research we consider a broader notion of 'anchoring' behavior allowing for short-run forecast horizons. However, unlike the previous literature we explicitly allow our model for the possibility that inflation targets are part of the households' inflation expectations formation. Furthermore, the sample period covers the current economic crisis in the Eurozone, thereby, enabling us to consider any possible variations in households' inflation expectations formation. Secondly, we also investigate the heterogeneity of households' behavior by distinguishing inattentiveness and anchoring between different demographic groups. As Dovern et al (2012) show, disagreements between professional forecasters are an important aspect of assessing their anchoring behavior. The present investigation outlines and distinguishes between both the aggregate and disaggregate approach. Thirdly, the current analysis distinguishes between the short- and long-run dynamics of households when form inflation expectations. It not only incorporates the excess sensitivity of household expectations formation but also their adjustment dynamics. We find that in the short-run expectations tend to overshoot, or overreact, and, therefore, converge non-monotonically. Finally, the present analysis considers and 
finds that households update their expectations non-linearly - indicating that household inattentiveness tends to be state-varying.

The structure of the paper is as follows. The next section outlines the issues that will be considered in the light of the models' specification, and leads to a model which extends Carroll's epidemiological version of the 'sticky information expectations' model. Section 3 describes the dataset and reports some preliminary empirical results conducted either along the individual dimension in repeated cross-sections, or over time at the aggregate level. Section 4 extends the analysis to different categories. The surveyed households are grouped into pseudo-individuals whose categories are defined on the basis of the households' individual characteristics. In addition, we also allow for both heterogeneity and nonlinearities in the groups' behavior. Finally, Section 5 outlines the summary of the key results and draws the concluding points.

\section{Household inflation expectations, inattentiveness and anchoring: The theoretical framework}

In this section we consider the broader notion of 'inattentive' and 'anchoring' behavior which is more consistent with non-experts, or households, forming inflation expectations. This is done by extending the epidemiological version of households forming macroeconomic expectations (Carroll $(2003 ; 2006)$ ) which also enables us to consider the possible competing hypotheses. As shown in Easaw and Golinelli (2010), the epidemiological model can be extended readily to incorporate both the long- and short-run dynamics of household expectations formation. In the present analysis we also consider both the long- and short-run dynamics of household's year-ahead forecasts.

The extended version incorporates explicitly the inflation target as part of the long-run dynamics of households' expectations formation. Nevertheless, the excess sensitive test used to assess the anchoring behavior of agent's inflation forecasts argues these expectations should not be excessively sensitive to actual inflation or their own perceptions of current inflation ${ }^{2}$. Hence, households update their expectations

\footnotetext{
They can be assessed by comparing estimation results either across counties, as in Levin et al. (2004), or over time, as in Kelly (2008) and in Blanchflower and Mac Coille (2009). Also, while previous studies have only considered actual inflation, households' perception of current inflation should also be used, if available. There could be a number of reasons why households may form current inflation perceptions and base their actions on them. Actual inflation is only available with some lag and also individual households may experience different inflation levels given their respective consumption baskets and the official figures may only partially reflect this.
} 
independently of changes to the current (or the most recently published) inflation rate and/or to their perceptions of current inflation. It, therefore, focuses on the short-run dynamics of households' forming inflation expectations. The extended epidemiological model presented here accordingly incorporates both the long and short-run dynamics of households' inflation expectations formation.

A rational inattentive household imperfectly observes professional forecasts , which are assumed to be rational. Hence households have partial access to rational information (see Mankiw and Reis, 2002) which are 'absorbed' over time. The epidemiological model where households anchor on the professional forecasts can be depicted as follows:

$$
E_{t}^{h}\left(\pi_{t+1}\right)=\lambda E_{t}^{F}\left(\pi_{t+1}\right)+(1-\lambda) E_{t-1}^{h}\left(\pi_{t}\right)+\varepsilon_{t}
$$

where $E_{t}^{h}\left(\pi_{t+1}\right)$ are household inflation expectations and $E_{t}^{F}\left(\pi_{t+1}\right)$ denotes the professional forecasts, which individuals can learn from the media news and $\lambda$ the absorption rate. Equation (1), which assumes the dynamics of a simple partial adjustment mechanism, can be generalized in the error-correction (referred to as EC hereafter) specification, where short- and long-run dynamics are not restricted to share the same absorption (or adjustment) rate $-\lambda$, but allow for two different parameters, $\lambda_{I}$ and $\lambda_{2}$, which respectively drive the short- and the long-run dynamics: ${ }^{3}$

$$
\Delta E_{t}^{h}\left(\pi_{t+1}\right)=\lambda_{1} \Delta E_{t}^{F}\left(\pi_{t+1}\right)+\lambda_{2}\left[E_{t-1}^{h}\left(\pi_{t}\right)-E_{t-1}^{F}\left(\pi_{t}\right)\right]+\varepsilon_{t}
$$

The adjustment toward long-run levels requires $\lambda_{2}<0$. Under the restriction $\lambda_{1}+\lambda_{2}=0$ model (1) is nested in model (2). The rejection of the latter restriction is consistent with EC dynamics where short-run overshooting, or overreaction, could take place as households learn about professional forecasts. In fact, in the EC context of model (2), $\lambda_{1}$ is the impact effect of professional forecasts as households absorb and can be larger than one. Likewise, $-\left(\lambda_{1}+\lambda_{2}\right)$ has the same effect measured one month later, i.e. as households update their expectations in $t$ for $t+1$ to those of professional forecasts in $t-1$ for $t .^{4}$

\footnotetext{
3 A change in professional forecasts is defined as: $\Delta E_{t}^{F}\left(\pi_{t+1}\right)=E_{t}^{F}\left(\pi_{t+1}\right)-E_{t-1}^{F}\left(\pi_{t}\right)$; similarly for the update of households' inflation expectations, $\Delta E_{t}^{h}\left(\pi_{t+1}\right)$.

4 The explanatory variables of impact and one-month-later absorption parameters are $E_{t}^{F}\left(\pi_{t+1}\right)$ and $E_{t-1}^{F}\left(\pi_{t}\right)$. For the extension of Carroll's epidemiological model to the EC model see also Easaw and Golinelli (2010).
} 
Carroll's epidemiological model (1) can be easily extended to allow the possibility that households' expectations are formed incorporating their own inflation perceptions, the most recently available figure of the actual inflation rate ${ }^{5}$, and the inflation target $\pi^{\mathrm{T}}$ (which is assumed to be time invariant):

$$
\begin{aligned}
& E_{t}^{h}\left(\pi_{t+1}\right)=\lambda\left(\phi_{1} E_{t}^{F}\left(\pi_{t+1}\right)+\phi_{2} \pi_{t}^{P, h}+\phi_{3} \pi_{t-1}+\phi_{4} \pi^{\mathrm{T}}\right) \\
& +(1-\lambda) E_{t-1}^{h}\left(\pi_{t}\right)+\varepsilon_{t}
\end{aligned}
$$

Here households' inflation expectations are anchored potentially on the four measures with $\phi_{i}$ depicting the weights. The four possible anchors are: professional forecasts $(i=1)$, households' perceived inflation $\pi^{P, h}(i=2)$, actual inflation rate $\pi \quad(i=3)$, and the inflation target $(i=4)$. Households are assumed to form their expectations by switching between the variables above as dictated by the prevailing economic conditions and situation.

Equation (3) dynamics may be generalized to obtain the basic model for empirical investigation encompassing the different approaches of the anchoring literature (i.e. the short-run dynamics and excess sensitivity) and Carroll's epidemiological dynamics ${ }^{6}$ :

$$
\begin{aligned}
& \Delta E_{t}^{h}\left(\pi_{t+1}\right)=\lambda_{11} \Delta E_{t}^{F}\left(\pi_{t+1}\right)+\lambda_{12} \Delta \pi_{t}^{P, h}+\lambda_{13} \Delta \pi_{t-1} \\
& +\lambda_{2}\left[E_{t-1}^{h}\left(\pi_{t}\right)-\phi_{1} E_{t-1}^{F}\left(\pi_{t}\right)-\phi_{2} \pi_{t-1}^{P, h}-\phi_{3} \pi_{t-2}-\phi_{4} \pi^{T}\right]+\varepsilon_{t}
\end{aligned}
$$

where $\lambda_{1 i}(i=1,2,3)$ are three parameters measuring short-run fluctuations of households' expectations due to changes in professional forecasts $(i=1)$, in households' perceived inflation $(i=2)$, and in one-month lagged actual inflation $(i=3) ; \lambda_{2}$ is the speed of adjustment toward the long run; $\phi_{i}$ parameters are defined as in equation (3).

Similar to equation (2), the EC dynamics found in equation (4) can also allow for the overreaction of households expectations formed in $t$ for $t+1$ if $\lambda_{11}>-\lambda_{2}$ (i.e.

$5 \quad$ Actual inflation is one-month lagged in order to account for the publication delay of the official figures. In a recent paper, Lanne et al. (2009) introduces an extended or hybrid model of Carroll (2003) which similarly includes current inflation signals.

$6 \quad$ Here, for simplicity, we assume that households' expected inflation is generated by a first-order dynamics. During empirical analysis, if the test for residuals' autocorrelation of model (4) rejects the null, we can augment it with lags of the short-run regressors in differences to attain white noise residuals. 
$\frac{\lambda_{11}}{-\lambda_{2}}>1$ ). Concurrently, the overreacting households revise their expectations in $t-1$ for $t$ if $\frac{\lambda_{11}}{-\lambda_{2}}>\phi_{1} \cdot^{7}$

Inflation targets in model (4) are part of the long-run dynamics of households' year-ahead inflation expectations. However, assuming that the target is time invariant over the sample period, the constant in equation (4) corresponds to the parameter: $-\lambda_{2} \phi_{4} \pi^{T}$. This, however, does not allow us to identify two separate values for $\phi_{4}$ and $\pi^{T}$. It is not possible to verify whether $\pi^{T}$ is consistent with the inflation target, which in the present case is $2 \%$, i.e. the ECB quantitative definition of 'price stability'. Nevertheless, even if households anchor on this target, it can only be credible if $\phi_{4} \pi^{T}=2 \%$ or, alternatively, if $\phi_{4}=1$.

The remainder of the paper will focus on the empirical investigation of the model outlined here. The various issues and competing hypotheses are also considered using a number of restrictions tests.

\section{Measurement of the variables and a preliminary inspection to data}

The information on inflation perceptions and expectations that will be used troughout the paper is extracted from the monthly ISTAT Consumers survey, performed within the framework of the EC Harmonised project ${ }^{9}$. The survey mainly consists of qualitative questions on the personal situation of the consumer and the country. Questions allow five possible answers, ranging from strongly positive to strongly negative; results are usually expressed as weighted balances of positive and negative replies. The survey is conducted with a Computer Assisted Telephone Interviewing (CATI) system; it is based on a monthly sample of 2.000 Italian consumers, changing each month, for a total of 24.000 persons interviewed per year. The sample is extracted from the public telephone book registers and selected on the basis of a two-stage

\footnotetext{
$7 \quad$ Further explanations about the overreaction and revision are found in Appendix A1.

$8 \quad$ Since the beginning of its activity, the ECB did not adopt a proper inflation targeting strategy; however, according to its Statute, the main ECB mandate is to ensure 'price stability' in the Euro area. The ECB has provided a quantitative definition of price stability, i.e. any increase of the HICP below $2 \%$ for the whole Euro area to be complied within a medium term perspective (for a presentation of the monetary policy strategy of the ECB, see e.g. Scheller, 2006, section 3.1.2). In this sense we can interpret the 2\%-threshold, as measured by the Euro-area HICP, as an implicit target for ECB monetary policy.

$9 \quad$ For a more comprehensive description of the harmonised EU programme see European Commission (2006).
} 
technique: in the first step, it is stratified according to zone of residence and size of municipalities; the second stage is based on the selection of a specific consumer within the household selected in the first step. This selection is based on quota sampling according to gender (48,5\% males, 51,5\% females).

Quota sampling ensures that sample size is always equal to the target, substituting non response with other consumers extracted from the sample; the response rate of the survey, calculated as the ratio among the number of the respondents and that of total monthly contacts has been equal to about $66 \%$ in recent years. Individual replies are aggregated with a double-weighting system based on probability and post-stratification weights. Probability weights - i.e., the inverse of the selection probability - are used to correct for possible selection bias associated with the nature of the reference list and the size of the family; post stratification weights correct for possible representativeness problems stemming, for instance, from the fact that women are easier to contact than men, or unemployed and retired people than employee or self-employed (other information is available in Malgarini, 2009). Since February 2003 two questions have been added to the traditional qualitative monthly questionnaire, asking consumers to provide quantitative estimates of their perceived and expected inflation (see Biau et al., 2010); the available dataset has a total of 93 monthly observations, from February 2003 to October 2010. .

The two questions concerning quantitative inflation perceptions and expectations are the following: ${ }^{10}$

Q51 By how many per cent do you think that consumer prices have gone up/down over the past 12 months? (Please give a single figure estimate).

Consumer prices have increased by $\square \square \square, \square \%$ / decreased by $\square \square \square, \square \%$.

Q61 By how many per cent do you expect consumer prices to go up/down change in the next 12 months? (Please give a single figure estimate).

Consumer prices will increase by $\square \square \square, \square \%$ / decreased by $\square \square \square, \square \%$.

Quantitative evaluations are asked as a single figure estimate. The questionnaire asks for confirmation if answers exceed a $20 \%$ threshold $^{11}$; moreover, answers are bounded within the range $\pm 100 \%$. Participation rates to quantitative questions have been

\footnotetext{
10 The IISTAT survey provides point forecasts about inflation expected for 12 months ahead; no information is available on individual uncertainty about future inflation. On the significance of that kind of information in evaluating Central Bank credibility, see for instance De Bruin et al. (2009).

11 In its survey, the University of Michigan asks for confirmation if the answer is greater than $5 \%$.
} 
rather high on average, being equal to almost $88 \%$ for assessments and $84 \%$ for forecasts in the period considered.

In the following, the individual inflation expectations over the next 12 months and the individual inflation perceptions over the past 12 months are respectively denoted as $E_{t}^{h}\left(\pi_{t+1}\right)$ and $\pi_{t}^{P, h}$.

The $h$ index in the labels above can alternatively represent (and measure):

1. the $\mathrm{N}$ monthly survey's individual answers — in this case $h=1,2, \ldots, \mathrm{N}$ (with $\mathrm{N}=2000$ households). Note that the whole information set is not a panel, as the same people are not interviewed repeatedly, but are simple repeat cross-sections of $\mathrm{N} \times \mathrm{T}$ observations, where we pool together all the available monthly surveys (cross-sections).

2. the monthly average of the $\mathrm{N}$ individual survey's answers - in this case the information set is a single time series of $\mathrm{T}=93$ monthly observations, $h=\mathrm{M}$ (which stands for 'mean').

3. we can average the $\mathrm{N}$ monthly answers in $\mathrm{G}$ groups (i.e. pseudo-individuals) defined on the basis of individual characteristics also reported by the survey (such as gender, age, education, and employment) - in this case $h=1,2, \ldots, \mathrm{G}$ (with $\mathrm{G}$ being much smaller than $\mathrm{N}$ ). The resulting information set is a pseudo panel of G×T observations; with Italian survey data see e.g. Malgarini et al. (2009).

In the Italian case, the professional forecast time series $E_{t}^{F}\left(\pi_{t+1}\right)$ lacks an obvious way to measure it, such as the Survey of Professional Forecasters for the US. For this reason, we had to compute a consensus forecast, defined as the average of the Italy's inflation forecasts made by different national and international institutes whose predictions are usually highlighted by the media as soon as they are issued. ${ }^{12}$

The actual inflation rate $\pi_{t}$ is measured by ISTAT with monthly time series based on either the national consumer price index (CPI), or the more recent harmonized index of consumer prices (HICP) to give comparable measures of inflation for Euroland countries. With any index of consumer prices monthly inflation may be alternatively measured by the growth rate of the index over the past 12 months (y-o-y)

12 Details are in Appendix A2.1 - A2.2. 
or by its annualized monthly growth rate (m-o-m); see e.g. Lanne et al. (2009). Both choices have its pros and cons: y-o-y growth is slightly more used and easy to communicate the inflation rate but implies a more complex dynamics (i.e. with moving average error terms which in turn may imply long autoregressive lags); viceversa m-o-m growth is slightly more difficult to communicate but its dynamics is easier to model. In the following parts we report results with both the annualized m-o-m growth rate of CPI and the y-o-y growth rate of HICP. As we will see, outcomes are robust to these alternative inflation measures.

Overall, the three alternative levels of aggregation of the survey data described above lead to very different information sets: (1) repeated cross-sections; (2) aggregate time series; (3) pseudo panels. In the following two sections, we will preliminarily analyze the main features of type (1) and (2) data, respectively.

\subsection{Analyzing the repeated cross sections data-set}

The first information set mentioned above is a repeated cross-sections for $E_{t}^{h}\left(\pi_{t+1}\right)$ and $\pi_{t}^{P, h}$ and not a panel. Therefore, it does not allow for the estimation of dynamic models such as those in Section 2 where individual inflation expectations and perceptions are lagged or in differences.

However, with such a large data-set (about 130,000 individual observations) we can assess whether average inflation expectations computed by individual characteristics (such as employment, education, gender, and age) are similar or tend to by related with some of the respondents' characteristics. Results are in Table 1, where columns (1)-(2) describe the sample composition (number of individuals and share over the total) of selected characteristics usually found in the literature to influence the formation of inflation expectations, and columns (3)-(4) report the corresponding unconditional means and standard deviations of inflation forecasts by characteristic.

\section{Table 1 here}

At a first look, the large disparity in the forecasts made by different groups clearly emerges, together with some regularities. For example, as with the findings of Malgarini (2009), expected inflation decreases with age and education (older people with a degree predict smaller price increases than those who are younger and less educated) and women expect higher rates of inflation than men. Similar results are often found in literature (see Bryan and Venkatu (2001a) for the US, and Blanchflower and 
Mac Coille (2009) for the UK), though some researchers find quite different outcomes, see Lombardelli and Saleheen (2003) for the UK.

Of course, being based on unconditional means, results in column (3) are related because individual characteristics are often mutually related too. For example, age, employment and income ${ }^{13}$ co-move since it is quite obvious that older people probably are no longer employed (pensioners), and - consequently — both groups tends to predict lower-than-average inflation rates.

In order to disentangle the (marginal) effect of a change in one characteristic, while other characteristics remain unchanged, in column (5) of Table 1 we report the estimates of a simple dummy variables model such as:

$$
E_{t}^{h}\left(\pi_{t+1}\right)=\alpha_{0}+\alpha_{k} D(k)_{t}^{h}+\varepsilon_{t}^{h}
$$

where observations about individual inflation expectations are regressed against the intercept and $k$ dummy variables equal to 1 if the corresponding individual has the $k^{\text {th }}$ characteristic, zero otherwise. In model (5), $k=11$ and the specific characteristics involved - listed along the rows of Table 1 - are: 4 for employment (self-employed, blue collar, pensioner, and other); 3 for education (university, lower-secondary, and elementary); 1 for gender (female); and 3 for age (less than 30, between 50 and 64, and over 64). The errors $\varepsilon_{t}^{h}$ are random shock reflecting idiosyncratic preferences.

The 11 characteristics mentioned above do not cover all the possible cases, for this the OLS estimate of the intercept $\alpha_{0}$ measures the mean of the inflation expectations of the individuals who do not have any of the previous 11 characteristics, i.e. the reference group. ${ }^{14}$ We set the reference group as: male aged 30-49 with upper secondary education and white-collar employee. Given the definition of reference group as that collecting high frequency cases, the average inflation rate expected for the reference group (measured by $\alpha_{0}$ parameter whose estimate is in the last row of column 5) is bound to be very close to the full-sample unconditional mean reported in the last row of column (3).

In model (5), the estimates of $\alpha_{k}$ represent the deviations of the mean inflation of each of the $k$ characteristics to that of the reference group (i.e. the estimate of $\alpha_{0}$ ).

\footnotetext{
13 Income was not used here because many observations would have been lost due to non responses. However, Malgarini (2009) finds that income, together with the size of municipality, does not affect inflation expectations.

14 The exclusion from the model of the dummies corresponding to the reference group characteristics prevents the insurgence of the dummy variable trap.
} 
On the basis of the t-statistics of the corresponding $\alpha_{k}$ estimates, we can test for the null hypothesis: $\alpha_{k}=0$ in order to formally assess for the significance of such deviations.

In the light of the results in column (5) of Table 1 we have that, apart from pensioners and people under 30, all other deviations from the reference group forecasts are at least $5 \%$ (very often 1\%) significantly different from zero. Being self-employed or aged over 64 induces the largest absolute deviations from the reference group: respondents belonging to these two categories hold more than $1 \%$ lower inflation expectations than that of the reference group (more than $1.5 \%$ per year for older people). Vice versa, less educated people expect about one percentage point more inflation than the reference group. We confirm the existence of significantly different inflation forecasts for men and women - though in a less pronounced way than Bryan and Venkatu (2001b).

Results reported in column (6) of Table 1 are based on the dummy variables model (6) which is only slightly different to model (5), as the intercept $\alpha_{0}$ is substituted by a common time pattern (the so called "time effects") represented by the sequence of 93 parameters $\alpha_{t}$ corresponding to 93 time dummies $\tau_{t}$ (one time dummy for each observed month-year in the sample):

$$
E_{t}^{h}\left(\pi_{t+1}\right)=\alpha_{t} \tau_{t}+\alpha_{k} D(k)_{t}^{h}+\varepsilon_{t}^{h}
$$

where $\tau_{t}$ is a dummy variable equal to 1 if the observation is in $t$, zero otherwise; each time effect $\alpha_{t}$ is the average expected inflation of the reference group for each time period. ${ }^{15}$ The interpretation of the parameters of interest $\alpha_{k}$ in model (6) is the same as in model (5), and the same is true for the random errors $\varepsilon_{t}^{h}$.

Overall, the estimation of model (6) parameters in column (6) of Table 1 suggests that the outcomes in column (5) discussed above are robust to the inclusion of 93 time effects. In other terms, the inclusion of a deterministic time pattern does not curb the significance of the individual characteristics' ability in explaining inflation expectations

\footnotetext{
$15 \quad$ Note also that $\sum_{t=1}^{93} \tau_{t}$ is a vector of ones, and that the average of the time effects (i.e. the 93
} estimates of $\alpha_{t}$ ) measures the average level over time of the reference group's inflation expectations. 
Finally, by using the same repeated cross-section dataset it is possible to further extend the explanation of the idiosyncratic shocks $\varepsilon_{t}^{h}$ of models (5) and (6) by adding in a new model (7) the perceptions of inflation over the twelve months preceding each survey date $\left(\pi_{t}^{P, h}\right)$, the consensus forecasts $\left(E_{t}^{F}\left(\pi_{t+1}\right)\right.$ ), and their interactions with the $k$ individual characteristics listed above:

$$
\begin{aligned}
& E_{t}^{h}\left(\pi_{t+1}\right)=\alpha_{t} \tau_{t}+\alpha_{k} D(k)_{t}^{h}+\alpha_{P} \pi_{t}^{P, h}+\alpha_{F} E_{t}^{F}\left(\pi_{t+1}\right)+ \\
& \alpha_{P k}\left[D(k)_{t}^{h} \times \pi_{t}^{P, h}\right]+\alpha_{F k}\left[D(k)_{t}^{h} \times E_{t}^{F}\left(\pi_{t+1}\right)\right]+\varepsilon_{t}^{h}
\end{aligned}
$$

where $\alpha_{P}$ and $\alpha_{F}$ are two parameters measuring the effect of $\pi_{t}^{P, h}$ and of $E_{t}^{F}\left(\pi_{t+1}\right)$ on the inflation forecasts of the reference group; $\alpha_{P k}$ and $\alpha_{F k}(k=1,2, \ldots, 11)$ are 22 parameters that represent the deviations to $\alpha_{P}$ and $\alpha_{F}$ effects for the reference group due to each of the $k$ characteristics.

If we group the 11 characteristics $k$ in the 4 categories $c$ listed in the first column of Table 1 (i.e. $c=$ employment, education, gender and age), we can test for significant deviations with respect to the reference group due to $c$ in the way the perceived inflation influences the inflation forecasts as: $H_{0}: \alpha_{P k}=0 \forall k \in c$, i.e. in terms of p-values of joint zero restrictions imposed to the parameters of each characteristic belonging to category $c$. The same can be tested for consensus inflation forecasts.

Along the three columns of data in Table 2, the main estimation outcomes are reported with reference to respectively: (a) model (5) with only individual characteristics (the same as that used in column (5) of Table 1); (b) model (6) with individual characteristics and time dummies (the same as that used in column (6) of Table 1); (c) model (7) which also adds the inflation perceptions, the consensus forecasts, and their interactions with the 11 individual characteristics defined so far. The last row in Table 2 highlights the increment in the number of parameters to be estimated going from the model in the first to that in the last column: model (6) adds 92 parameters to those in model (5), model (7) adds 24 parameters to those in model (6).

\section{Table 2 here}

Results in terms of p-values of joint zero restrictions imposed to the parameters of each category can be summarized as follows. In the last column of Table 2 it is evident that the very often significant introduction of the interactions between perceived inflation (and consensus forecasts) and individual characteristics curbs the statistical 
significance of the shifts due to the individual characteristics, while such shifts are largely significant in models (5) and (6) that do not have interactions; see the first two columns of Table 2 which mirror the outcomes in the last two columns of Table 1.

The significance of many 'incremental' regressors from model (5) to model (7) in Table 2 can be seen in terms of improvements in the models' explanatory ability when additional variables are added. In fact, model (5) with only individual characteristics is able to explain only a very small portion of the overall variability of individual inflation forecasts (in the first column of Table 2 the $\mathrm{R}^{2}$ is equal to 0.005) because it misses regressors able explain the evolution of expected inflation over time. Such time patterns can be captured, albeit in a rough deterministic way, by the inclusion of the time effects in model (6); consequently the explanatory ability rises to 0.184 . Finally, model (7) explanatory ability further rises to about 0.3 because of the presence of interactions among individual characteristics and the evolution over time of both the perceived inflation and the consensus inflation forecast.

On the basis of the evidence reported in this section, we preliminary support the view that individual characteristics induce heterogeneous behaviors by groups of individuals, rather than simple average shifts of expected inflation. In other terms, expected inflation is better explained by models in which group-specific parameters allow individuals to react with different speeds to the perceived and to the consensus inflation. Further, the better explanatory ability of models which embody regressors able to explain the evolution over time of households' inflation expectations stresses the need for an appropriate modelling of its dynamics.

\subsection{Aggregate time-series results}

Outcomes in the previous section are based on very simplified specifications of model (4), because repeated cross sections do not allow for dynamics of the surveyed variables, which on the other hand is a distinctive feature of the referenced literature. A way to introduce truly dynamic models using individual survey data is their aggregation

over individuals by defining the variables $E_{t}^{M}\left(\pi_{t+1}\right)$ and $\pi_{t}^{P, M}$ as the monthly averages of the corresponding individual answers:

$$
\begin{aligned}
& \Delta E_{t}^{M}\left(\pi_{t+1}\right)=\lambda_{11} \Delta E_{t}^{F}\left(\pi_{t+1}\right)+\lambda_{12} \Delta \pi_{t}^{P, M}+\lambda_{13} \Delta \pi_{t-1} \\
& +\lambda_{2}\left[E_{t-1}^{M}\left(\pi_{t}\right)-\phi_{1} E_{t-1}^{F}\left(\pi_{t}\right)-\phi_{2} \pi_{t-1}^{P, M}-\phi_{3} \pi_{t-2}-\phi_{4} \pi^{T}\right]+\varepsilon_{t}
\end{aligned}
$$


This aggregate approach is the most commonly used in the literature about modeling inflation expectations; see Carroll (2003), Lanne et al. (2009), and Mankiw et al. (2003), amongst others.

There are a number of possible restrictions to the general model (8) to verify the statistical performance of the nested models of the anchoring literature (i.e. excess sensitivity) and of the epidemiological dynamics. In particular, the inferences using models in first differences - as excess sensitivity literature does — are appropriate only if $\lambda_{2}=0$, as only in this case the levels of the explanatory variables can be excluded from the reference model of the test. Carroll's 'pure' epidemic dynamics in model (1) is a data congruent representation of the process generating the households' expectations only if the following restrictions are valid: $\lambda_{12}=\lambda_{13}=0, \phi_{2}=\phi_{3}=0$ (which exclude the role of actual and perceived inflation in both levels and first differences), plus $\lambda_{11}=-\lambda_{2}$ and $\phi_{1}=1$ (which collapse the dynamics in a simple partial adjustment). ${ }^{16}$

At the aggregate level, equation (8) can be seen as a first-order autoregressive distributed lag (ARDL) model. This allows us to model the relationship without needing to establish a priori the variables as $\mathrm{I}(1)$ or $\mathrm{I}(0)$ due to the findings of Pesaran et al. (2001), henceforth PSS. The PSS approach is appropriate here, because the three explanatory variables of our ARDL model can be considered as the forcing levels of households' inflation expectations in the light of exogeneity tests both in the stationary (Hausman, 1978) and in the non-stationary (Johansen, 1992) context: we never reject the null with p-values well above $20 \%{ }^{17}$

In the PSS framework, the $5 \%$ critical values of $\lambda_{2}$ t-statistic to test for the existence of a relationship among the levels of the variables of interest are -2.86 and 3.78 for $\mathrm{I}(0)$ and $\mathrm{I}(1)$ regressors, respectively.

Estimation results of model (8) as well as the outcomes of the general-tospecific modeling approach are reported along the columns of Table 3. More explicitly, the first two columns of Table 3 report the estimates of two alterative specifications of

\footnotetext{
16 On the latter point, see also Appendix A1.

17 The unreported results of the paper are available upon request from the authors, together with the corresponding procedures to implement them. From the point of view of the information content of the three variables of interest, there cannot be feedback from the levels of households' forecasts to past actual inflation, to professional forecasts (as they release their forecasts before households are surveyed), and to households' inflation perceptions (which regard past 12 months while expectations regard next 12 months). Given that in the latter case both variables may be driven by the same moods as they are surveyed at the same time, we validated the exogeneity assumption using the exogeneity tests discussed above.
} 
the "general" model (8) - i.e. with two alternative measures of the actual inflation rate then, in the following columns, we restrict to zero the parameters whose estimates were previously not significant; the aim of this gradual model reduction is to report evidence about the robustness of the role played by our "core determinants" (i.e. dynamics, perceived inflation - but only in the short run -, and consensus forecasts) independently on the presence or not of the other, not significant, regressors (i.e. levels of perceived inflation and the actual inflation rate). Not reported residuals' misspecification test results suggest that one lag is enough to obtain well behaved (i.e. i.i.d) residuals for all the estimates in Table 3.

\section{Table 3 here}

Overall, the model explains more than $35 \%$ of the changes in the inflation expectations variability over the period 2003m3-2010m10, which corresponds to about $85 \%$ of the levels in the inflation expectations variability. ${ }^{18}$

We identify five main results. First, a level relationship exists between households' inflation expectations and consensus forecasts irrespective of the integration order of the regressors, as shown by all the t-statistics of $\lambda_{2}$ estimates in Table 3 that range from -4.44 to -4.28 . This outcome questions the appropriateness of making inferences about anchoring on the basis of models in differences. Instead, Carroll's epidemiological model is only partially survey data congruent because, though it assumes the existence of level-relationships, its partial adjustment dynamics implies restrictions on error-correction parameters which are always rejected by data. The estimates of the speed of adjustment $\lambda_{2}$ (around -0.3) suggest that about $30 \%$ of the gap between actual and target levels of inflation expectations is closed in the first month and, consequently, that the target inflation levels are met in the first year after the shock. This high speed of adjustment is coherent with the forecast horizon and makes quite informative the short span of available data (93 months from 2003 to 2010). In addition, it is also worth noting that - albeit short - our sample has the advantage of covering only the period following the changeover of January 2002, with less probable biases due to the occurrence of structural changes. In order to formally test for constancy of the parameters estimated in columns (4) and (5), we run both Andrews (1993) endogenous

18 Of course this $\mathrm{R}^{2}=0.85$ of model (8) cannot be compared with the (apparently) strongly lower 0.3 of model (7) because here the averaging of individual data over individuals in period means dramatically reduced the sample variability. 
breakpoint test (with 10\% observations trimming), and Chow (1960) predictive failure test assuming the last cyclical peak (occurred in August 2007) as the exogenous breakpoint. In this way, we leave in the second part of the sample the financial crisis period, which is a good candidate for inducing a structural break. The statistics never reject at 5\% the null hypothesis of parameters' constancy with p-values of the Andrews endogenous breakpoint test equal to $8.3 \%$ and to $64.4 \%$ in column (4) and (5), i.e. for the restricted model with and without the intercept, and with p-values of the corresponding Chow predictive failure test equal to $11.0 \%$ and to $37.2 \%$. It is also worth noting that, albeit not 5\% significant, the maximum likely break point with the Andrews endogenous breakpoint procedure is dated in January 2008, i.e. quite close to the exogenous date we set for the Chow test, supporting the idea that in our sample the financial crisis is the most relevant event also from the point of view of the stability of the mechanism of forming inflation expectations.

Second, households significantly overreact to professional forecasts in $t$ for $t+1$, and they do not revise such overreaction based on professional forecasts in the past month. This is largely due to estimated $\phi_{1}$ (i.e. impact effect of professional forecasts) being well above one, making the revision test more restrictive than the overreaction one. In short, informed households' behavior may be characterized as short-run overreaction.

Third, among the regressors of model (8), the actual inflation rate never plays a significant role. The finding is robust to the specific measure adopted for the actual inflation rate: either the model with annualized month-on-month growth of CPI in column (1), or that with year-on-year growth of HICP in column (2) never reject the null hypothesis $\lambda_{13}=\phi_{3}=0$ with p-values equal to $22.6 \%$ and $64.5 \%$ respectively. The comparison between the unrestricted estimates in columns (1)-(2) and the restricted in column (3) suggests that the exclusion from the model of the latest known figure of the inflation rate does not entail significant changes in the estimates of the other parameters.

Fourth, not all the three regressors of model (8) - consensus forecasts, perceived and actual inflation rates - play a significant role in shaping households' expected inflation level relationship, see the $\phi_{i}$ (with $i=1,2$, and 3) estimates in columns (1), (2) and (3) of Table 3. The effect of consensus on individual forecasts is considerably large and significant, suggesting a strong reactivity of the levels of households' expectations to it, while the other two drivers do not play any appreciable 
role. After imposing the corresponding exclusion restrictions, the mean individual $M$ 's (i.e. aggregate) model (8) collapses to:

$$
\begin{aligned}
& \Delta E_{t}^{M}\left(\pi_{t+1}\right)=\lambda_{11} \Delta E_{t}^{F}\left(\pi_{t+1}\right)+\lambda_{12} \Delta \pi_{t}^{P, M} \\
& +\lambda_{2}\left[E_{t-1}^{M}\left(\pi_{t}\right)-\phi_{1} E_{t-1}^{F}\left(\pi_{t}\right)-\phi_{4} \pi^{T}\right]+\varepsilon_{t}
\end{aligned}
$$

where the short-run changes in households' expectations are driven by both changes in professional forecasts and in current inflation perceptions; the corresponding estimates are in column (4) of Table 3.

Fifth, the interval estimation of the explicit (constant) target effect $\phi_{4} \pi^{\mathrm{T}}$ is wide, ranging from negative to positive values, then not significantly different to zero. However, this fact cannot exclude anchoring on the (implicit) target passes through professional forecasters' behavior. Under the assumption that the intercept is zero, estimates are reported in column (5) of Table 3.

We can exploit the steady state solution of the consensus inflation forecasts modelled as a simple AR model ${ }^{19}$ to measure the corresponding households expected inflation as:

$$
E^{M}\left(\pi^{*}\right)=\phi_{1} E^{F}\left(\pi^{*}\right)+\phi_{4} \pi^{T}
$$

Columns (4) and (5) in the lower part of Table 3 report the steady state solution in equation (10) on the basis of the consensus steady state $95 \%$ confidence interval which goes from $1.7 \%$ to $2.1 \%$. Results suggest a $4.7-6.2 \%$ range to which households' inflation forecasts converge in absence of short term shocks. These high figures mirrors what surveyed households report for both inflation perceptions and expectations, see Section 3.1.

\section{Modeling inflation expectations with pseudo-panel data}

The exploratory analysis in the previous section highlights two important findings regarding Italian households' formation of inflation expectations: firstly, groups of individuals, selected on the basis of pre-defined personal characteristics (such as education, gender and age), seem to approach inflation forecasts in different ways, leading to quite different levels of expected inflation, that have the common feature of being considerably higher than the actual inflation figures.

19 The full discussion is in Appendix A2.2. - A2.3 
Secondly, at an economy-wide level (i.e. by using single time series of monthly averages of all the survey respondent), the dynamics of households' inflation expectations follow in the short run changes in both consensus forecasts and perceived inflation over the recent past, while in the long run they are solely driven by the level of consensus of the professional forecasters. The long-run solution of the aggregate model suggests that households' inflation expectations fall in a range well above the $2 \%$ ECB long-run inflation target, despite consensus forecasts that closely point to the $2 \%$ long run level ${ }^{20}$.

However, two drawbacks affect the methodologies that we followed to obtain these results: (1) on the repeated cross-section level, the lack of time dimension of individual data prevented us from estimating appropriate dynamic relationships which, instead, are an essential ingredient of both sticky-information and epidemic inflation expectation theoretical models; (2) on the aggregate time-series level, modeling results may be biased because of the parameters' heterogeneity across groups.

In this section we will check the extent to which previous drawbacks may have corrupted our main findings. To do this, we will base our analysis on pseudo panels obtained by averaging individual data in groups whose categories are selected on the basis of the individual characteristics outlined in Tables 1 and 2.

In defining the aggregation categories, we have to acknowledge that the number of surveyed individuals belonging to each pseudo panel's group must be large enough to preserve the statistical properties of the pseudo-panel estimators (see Veerbek and Nijman, 1992). In addition, the unavoidable arbitrariness of any category definition suggests testing for the robustness of main findings to alternative ways of grouping individual observations. In this research, we define four alternative pseudo-panels with 7-10 groups each; details about the groups’ definitions are in Table 4.

\section{Table 4 here}

\subsection{Pooled mean group estimator for heterogeneous linear models}

Given that the time span of our data is quite wide and homogeneous ( $T=93$ months, covering the post monetary changeover period) we estimated model (4)

20 In a recent study, Beechy et al. (2011) found that professional inflation forecasters in the Eurozone are more firmly anchored than their US counterparts and concluded that this is largely due to explicit inflation targeting from the ECB. 
parameters under the assumption of full heterogeneity, i.e. a complete set of estimates is obtained for each panel's group. The model (4) heterogeneous specification is:

$$
\begin{aligned}
& \Delta E_{t}^{h}\left(\pi_{t+1}\right)=\lambda_{11}^{h} \Delta E_{t}^{F}\left(\pi_{t+1}\right)+\lambda_{12}^{h} \Delta \pi_{t}^{P, h}+\lambda_{13}^{h} \Delta \pi_{t-1} \\
& +\lambda_{2}^{h}\left[E_{t-1}^{h}\left(\pi_{t}\right)-\phi_{1}^{h} E_{t-1}^{F}\left(\pi_{t}\right)-\phi_{2}^{h} \pi_{t-1}^{P, h}-\phi_{3}^{h} \pi_{t-2}-\phi_{4}^{h} \pi^{T}\right]+\varepsilon_{t}^{h}
\end{aligned}
$$

where $h=1,2,3, \ldots, G$ (with $G=7$ for the first panel definition, 8 for the second, 10 for the third, and 8 for the fourth; see Table 4).

The estimation of the panel heterogeneous models by group (i.e. by each $h$ ), and the following analyses were conducted by broadly using the same methodology as that with aggregate time series. Results obtained with panel \# 1 to \# 4 are reported in Tables 5-8, respectively.

\section{Table 5 here}

Starting from the heterogeneous estimates of model (11) parameters with panel \# 1 , the existence of a level relationship among the variables of interest, i.e. $\lambda_{2}^{h} \neq 0$ is assessed through the outcomes in the first two rows of Table 5, where $\lambda_{2}^{h}$ estimates and the corresponding $t$-statistics are reported. The critical values to be used for testing the null of absence of level relationships by group are again those of PSS (i.e. -2.86/-3.78). Results clearly indicate that the presence of levels is extremely relevant to have a congruent representation of data, as also found with aggregate time series. Given that not all the parameters of model (11) are significant, the following six rows of Table 5 report the p-values of number tests for the joint significance of the parameters which measure the short- and long-run effects of the actual inflation rate, and the levels of the perceived inflation. Similar to the aggregate time series, we performed these tests on models where the actual inflation rate are measured alternatively by the annualised m-o$m$ growth of CPI and by the y-o-y growth of the HICP.

With the exception of the elementary-level educated respondent when the actual inflation is measured by the "easier to track" y-o-y HICP growth, these parameters are jointly never significant. Therefore, we restricted them to zero, i.e. $\lambda_{13}^{h}=\phi_{2}^{h}=\phi_{3}^{h}=0$. These restrictions, lead to the following parsimonious and data-congruent model:

$$
\begin{aligned}
& \Delta E_{t}^{h}\left(\pi_{t+1}\right)=\lambda_{11}^{h} \Delta E_{t}^{F}\left(\pi_{t+1}\right)+\lambda_{12}^{h} \Delta \pi_{t}^{P, h} \\
& +\lambda_{2}^{h}\left[E_{t-1}^{h}\left(\pi_{t}\right)-\phi_{1}^{h} E_{t-1}^{F}\left(\pi_{t}\right)-\phi_{4}^{h} \pi^{T}\right]+\varepsilon_{t}^{h}
\end{aligned}
$$


Estimates of the relevant parameters (together with the t-statistics) and the goodness-offit measures of each equation are reported in Table 5. It is worth to note that almost always the parameters of model (12) do not reject the null hypothesis of no breaks in the light of both Andrews (1993) and Chow (1960) tests that were run here with the same settings described in the aggregate time series section.

For even more efficient inferences, we can use the Pesaran et al. (1999) approach of the pooled mean group estimators (PMG) if poolability tests allows for it. Under the PMG assumption, all the coefficients involved by the level-relationship are constrained to be identical across groups, i.e. $\phi_{1}^{h}=\phi_{1}$, while short-run coefficients $\lambda_{11}^{h}, \lambda_{12}^{h}, \lambda_{2}^{h}$, and variances of errors $\varepsilon_{t}^{h}$ are still allowed to be heterogeneous; in symbols, our PMG model is written as:

$$
\begin{aligned}
& \Delta E_{t}^{h}\left(\pi_{t+1}\right)=\lambda_{10}^{h}+\lambda_{11}^{h} \Delta E_{t}^{F}\left(\pi_{t+1}\right)+\lambda_{12}^{h} \Delta \pi_{t}^{P, h} \\
& +\lambda_{2}^{h}\left[E_{t-1}^{h}\left(\pi_{t}\right)-\phi_{1} E_{t-1}^{F}\left(\pi_{t}\right)\right]+\varepsilon_{t}^{h}
\end{aligned}
$$

where: $\lambda_{10}^{h}=-\lambda_{2}^{h} \phi_{4}^{h} \pi^{T}$ represents some sort of time-invariant group effects.

The inability to reject the restrictions that allow for the reduction from model (12) to (13), suggests that the maximum-likelihood method applied to PMG parameters is the most efficient estimator to make inferences about the determinants of households' expected inflation.

The PMG model always rejects further restrictions on the heterogeneous intercepts (i.e.: $\phi_{4}^{h}=\phi_{4}$ and $\phi_{4}^{h}=0$ ), which in our context contributes to the measure of the targeting effect. Therefore, the last two rows of Table 5 report intervals for the steady state solution which differ by group. These intervals of the long-run expected inflation are based on the same steady state consensus forecast confidence interval of $1.7-2.1 \%{ }^{21}$, which we also used to compute the expectations' steady state solution with aggregate data.

Though the amplitude of the interval is always the same (about 1.5\%), the steady state inflation expectations markedly differ by groups, as it is lower for the higher educated, with the university-educated having the lowest; the impact of working/not

$21 \quad$ Again, for details see Appendix A2.3. 
working condition is not clear cut. Nevertheless, it is always considerably higher than that of the professional forecast for the period under consideration. ${ }^{22}$

The pseudo individuals' absorption rates (i.e. the negative of the speed of adjustment $-\lambda_{2}^{h}$ ) vary considerably for working/non working status and education, ranging from 0.80 to 0.31 . University-educated individuals have the highest absorption rates with those not working absorbing a fifth faster. Conversely, those with elementary and lower secondary education adjust to the consensus forecasts considerably slower due to lower absorption rates. Nevertheless, those with lower secondary education who are in work are twice as fast as those not working. This group will not only be involved in wage negotiations but have greater opportunities for the social transmission of professional forecasts through interacting with others, especially in the workplace.

With regards to the overreaction dynamics, the lower part of Table 5 also reports the $P$-values of the two overreaction tests. ${ }^{23}$ Even though the simple overreaction model, which we found in the aggregate time series case, generally tends to prevail, the highest educated workers tend to depict the fully articulated dynamics of both short-run overreaction and overshot revision.

The results with pseudo panel \# 1 in Table 5 can be verified by repeating the same procedure for the alternative groups. The different groups in panel \# 1 were selected on the basis of the individuals' education and employment. The two alternative panels are defined by crossing these two characteristics with gender; in particular, panel \# 2 is defined on the basis of education and gender, and panel \# 3 on the basis of employment and gender. Finally, given that age also played a significant role in crosssection regressions, we also defined panel \# 4 on the basis of age and gender.

Results using panels \# 2 to \# 4 are reported in Tables 6 to 8 which have the same structure as that of Table 5, since the methodological design is the same as that we followed and discussed with panel \# 1.

\section{Tables 6-8 here}

\footnotetext{
22 The estimation of a constant (steady state) inflation rate expected by the Italian households is statistically sounded if expected inflation is stationary in our pseudo-panels. For this, we also tested for unit roots in our $E_{t}^{h}\left(\pi_{t+1}\right)$ pseudo panels by using the Im et al. (2003) heterogeneous panel test. Not reported results further corroborate the assumption of stationary inflation expectations. This outcome is in accordance with the existence of a level relationship between individual expectations and consensus forecasts because we found the latter stationary too.
}

$23 \quad$ For a full description, see Appendix A1.2. 
Here again, the first-order dynamics adequately represents the data and that the existence of a level-relationship between individual expectations and consensus forecasts is always evident for all groups, irrespective of the alternative panel definition. Finally, the fully heterogeneous model (12) can always be restricted to the PMG model (13) with p-values above 0.9, and, again, constant terms cannot be restricted neither to zero, nor to the same value across groups within each panel. As before, the results are robust to the use of alternative measures of actual inflation, and do not present warnings about their constancy over time.

Table 6 reports the findings for households with different educational backgrounds and distinguishing between males and females. As in the previous case, the absorption rates are highest for those who are university educated. The remaining households' absorption rates are considerably lower ranging between 0.49 and 0.36. The steady state inflation expectations one year ahead are lowest for males who are university educated but their female counterparts have long-run expectations that are more than $1 \%$ higher. The gender difference is evident for all groups but vanishes for the lower educated. The simplest overreaction dynamics without overshot revision prevails, with exceptions for higher educated males.

Table 7 and 8 reports the results for households based on occupation and age, also making gender comparisons for the various groups. Absorption rates are highest for the self-employed and female blue-collar workers and lowest for pensioners. It is unsurprising that the self-employed have the highest absorption rates. This group (probably more so than any of the others) have to deal with their own personal finances and engage in price (or wage) setting. Those aged between 50 and 64 also have higher absorption rates. So do males under 30. The difference between males and females are also pronounced, with the exception of those aged between 30 and 49 .

In the steady state solution, the amplitude of the interval for expected inflation one year ahead is always more or less the same (about 1-1.5\%), while the two extremes change with individuals' characteristics: the lower intervals (about 3.5/5.0) correspond to males either with a degree (see the first column in Table 6) or self-employed (see the first column in Table 7). Females have steady state expectations almost always above those of males, but the distance between males and females tend to decrease with age , for oldest people being virtually the same. The fully articulated overreaction dynamics seems to affect only the behavior of the youngest and oldest males. 
The absorption rates of households vary considerably. In general, the higher the education level the higher the absorption rate of the professional forecasts, because the most educated group has a better understanding of inflation forecasts and a wider access to the mass media which report them. If the transmission of the relevant information takes place socially, it is likely that this group will have professional and social networks that are equally knowledgeable.

The estimates also indicate significant differences between the different demographic groups' long-run expectations. This is most pronounced between the genders. Females have considerably higher inflation expectations than their male counterparts. Bryan and Venkatu (2001b) found that females had higher perceptions of inflation than males, and they also suggest number of possible reasons why this may arise. Females have different shopping patterns than men, both with respect to what they purchase (as females are more likely to do the household shopping) and with respect to the frequency of their purchases. Nevertheless, these reasons remain speculative.

Overall, there are no clear patterns for which households may overreact. The feature of overreaction is found across education levels, occupation and age (an interesting exception is blue-collar workers). Nevertheless, the lack of overreaction is more prevalent amongst females. In six out of the nine categories, females do not display behavior consistent with overreaction. Such a clear demographic distinction is again only found in the respective households' expectations long-run dynamics. Female groups are found to have higher long-run expectations. One possible inference that can be made is that households with higher long-run inflation expectations tend not to overreact when updating their expectations. As highlighted earlier in this subsection, the reasons why females have higher long-run expectations remain speculative and, therefore, so must their reasons for not overreacting. Nevertheless, maybe it is unsurprising that higher long-run inflation expectations are consistent with a lack of overreaction when updating takes place in the short-run.

In an innovative recent paper Fuhrer (2012) took new approach by including actual survey expectations in a DSGE model found that it performed considerably better exhibiting strong correlations to key macroeconomic variables. Consequently, he proposes methods for endogenising survey expectations in general equilibrium macro models improving monetary policy. Clearly, this suggests greater understanding the nature and dynamics of survey expectations. Hence, the heterogeneity amongst different demographic groups and the non-monotonic convergence of expectations found in the 
present analysis give clearer insights into how to generate better general equilibrium macro models and understanding actual inflation dynamics and persistence.

\subsection{Extensions with nonlinearities}

So far we have assumed the anchoring behavior of households' inflation expectations to be linear. Presently we will extend the basic linear model to consider non-linear relationships. In the preceding empirical investigations, we were unable to establish any significant relationship between current inflation signals and households' expectations in the long-run as found in Carroll (2003) and Lanne et al. (2009). We now consider whether such inflation signals are better depicted as a non-linear relationship. Current inflation figures together with professional forecasts enables households to determine the future direction, or momentum, of inflation rates and this may have an asymmetric effect on households’ expectations.

The future direction — or momentum — of inflation expectations is defined as the difference between consensus forecasts given at time $t$ for the next twelve months and the most recently available inflation rate, that is the inflation rate in $t-1$ It could be that, among the others effects, households' expectations also account for such a change in direction: when the difference is positive, the future inflation rate is expected to go up with respect to 'present' values. In addition, it could also be that the perception of such distance depends on how clear the forecasters' signal is to the general public, measured as the monthly standard error of single-institutes' forecasts. In symbols, we can define it as:

$$
\operatorname{gap}_{t}=\frac{E_{t}^{F}\left(\pi_{t+1}\right)-\pi_{t-1}}{s e_{t}^{F}\left(\pi_{t+1}\right)}
$$

which represent the standardized gap between the consensus forecast over the next year and the most recent known inflation rate, henceforth we will label it as simply a 'gap'. Since all the professional forecasters refer their inflation predictions to the y-o-y growth of CPI, we computed the gap on the basis of this specific measure of actual inflation.

In the first part of each panel of Table 9, we report the p-values of gapaugmenting the PMG models (13) previously estimated in a linear fashion, both in levels and first differences. With all the four data-sets, gap-additions are never significant. A possible explanation for such lack of significance is that the 'gap effect' enters in a nonlinear way into our relationship, rather than being linear. 
For this reason, we extended the linear PMG model (13) with nonlinear effects driven by the Heaviside indicator function $I_{t}$, which is based on the sign of the gap variable defined by equation (14)

$$
\begin{aligned}
& \Delta E_{t}^{h}\left(\pi_{t+1}\right)=\lambda_{10}^{h}+\lambda_{11}^{h} \Delta E_{t}^{F}\left(\pi_{t+1}\right)+\lambda_{12}^{h} \Delta \pi_{t}^{P, h}+\lambda_{14}^{h} \Delta \operatorname{gap}_{t} \\
& \left.+\left(\lambda_{2 P}^{h}+\lambda_{2 N}^{h} I_{t-1}\right)\left[E_{t-1}^{h}\left(\pi_{t}\right)-\phi_{1} E_{t-1}^{F}\left(\pi_{t}\right)-\left(\phi_{5}+\phi_{6} I_{t-1}\right) g a p_{t-1}\right)\right]+\varepsilon_{t}^{h}
\end{aligned}
$$

where $I_{t}=1$ if $\operatorname{gap}_{t-1}<0$ and $I_{t}=0$ if $\operatorname{gap}_{t-1} \geq 0$. In this context, a positive gap (i.e. consensus predicts inflation to go up during the next year) implies that households' long-run reactivity to such consensus is $\left(\phi_{1}+\frac{\phi_{5}}{s e_{t}^{F}}\right)$, with a speed of adjustment equal to $\lambda_{2 P}^{h}$. While a negative gap (when future inflation is expected to go down) implies a long-run reactivity equal to $\left(\phi_{1}+\frac{\phi_{5}+\phi_{6}}{s e_{t}^{F}}\right)$, with a speed of adjustment equal to $\left(\lambda_{2 P}^{h}+\lambda_{2 N}^{h}\right) .^{24}$

Given that not all the parameters measuring the nonlinear extensions from model (13) to model (15) are significant, after a number of tests (reported in Table 9) we define the following data congruent model that embodies a number of not rejected restrictions:

$$
\begin{aligned}
& \Delta E_{t}^{h}\left(\pi_{t+1}\right)=\lambda_{10}^{h}+\lambda_{11}^{h} \Delta E_{t}^{F}\left(\pi_{t+1}\right)+\lambda_{12}^{h} \Delta \pi_{t}^{P, h} \\
& \left.+\left(\lambda_{2 P}^{h}+\lambda_{2 N} I_{t-1}\right)\left[E_{t-1}^{h}\left(\pi_{t}\right)-\phi_{1} E_{t-1}^{F}\left(\pi_{t}\right)-\phi_{5}\left(1-I_{t-1}\right) g a p_{t-1}\right)\right]+\varepsilon_{t}^{h}
\end{aligned}
$$

The additional restrictions (and in particular $\phi_{5}+\phi_{6}=0$ ) suggest that long-run anchoring of household inflation expectations to consensus remains the same, that is $\phi_{1}+\frac{\phi_{5}}{s e_{t}^{F}}$ when the gap is positive. ${ }^{25}$ When gaps are negative it simplifies to $\phi_{1}$. The absorption rates remain the same as before. The results in Table 9 unambiguously suggest that both $\lambda_{2 N}$ and $\phi_{5}$ are $>0$. Positive gaps are associated with a higher longrun anchoring of households' expectations to consensus ( $\phi_{5}>0$ ) and faster absorption $\left(\lambda_{2 N}>0\right)$. The absorption rates of all households increases during periods when consensus inflation expectations are greater than the latest inflation rates. Indeed, the

\footnotetext{
$24 \quad$ In our sample $s e_{t}^{F}$ is in the $0.07 / 0.53$ range, with an average of 0.22 .

25 We estimated the long-run effects of consensus on inflation expectations at the average value of $s e_{t}^{F}$.
} 
female self-employed absorb perfectly during these periods, while the female bluecollar and 'other' male are close to perfect absorption. The relative weights (or ratio) placed on professional forecasts are also higher during these periods. Also note that the consensus long-run effect when the gap is positive $\left(\phi_{1}+\frac{\phi_{5}}{s e_{t}^{F}}\right)$ is higher. For example, the homogeneous long-run effect reported in Table 9 (panel \#1) is estimated at average $s e_{t}^{F}(0.22)$ and it is equal to 6.02, while a larger $s e_{t}^{F}=1$ would drop the estimate above to 3.87 .

\section{Table 9 here}

Broadly, the overreaction dynamics found in the nonlinear extensions mimics the linear specification. The exceptions are the university educated (those who are not in work and females), elementary education and those over the age of 64 (both genders). Regardless whether overreaction exists, there is no asymmetry between the two regimes. On the other hand, there is some asymmetric revision to overreaction. Revision is more likely when the gap is negative, that is when inflation is expected to have less momentum.

Overall, among different panels of data (whose pseudo-individuals are defined in alternative ways) the long-run parameter (homogeneous) estimates in Table 9 are remarkably similar, reinforcing the poolability test outcomes and suggesting a population where a number of parameters are constant across individuals.

If consensus forecasts and actual inflation rate converge to the same steady state solution, the gap goes to zero, and the formulation for the steady state expected inflation depicted in equation (10) is once again valid here. It is noteworthy that the last two lines of each panel in Table 9 indicate that the inclusion of nonlinear effects, which vanishes in the long run under the assumption of the unbiasedness of the consensus forecasts, lowers the steady state level of households' expected inflation over the next year. Nevertheless, it is still permanently above the steady state consensus inflation forecast solution.

Another important aspect of the present analyses is to investigate the nonlinear behavior of households when forming inflation expectations. Similar to Carroll (2003) and Lanne et al. (2009), we consider the role of current inflation rates. Unlike previous research, we consider the nonlinear impact of current inflation signals. We find that inflation signals are important to households as they are interested in the future direction 
of inflation rates, that is its momentum. Indeed, they respond asymmetrically. All households' absorption rates and their reactivity to consensus forecasts increase considerably during periods when the consensus for future inflation is higher than the present one. Akerlof et al. (1996; 2000) argue that households are more concerned about rising inflation as this would be more costly to them, because rising inflation usually leads to a fall in real wages. The state-varying nature of household inflation expectations better explain the how households update their expectations and inattentiveness which, inevitably, transpires into the dynamics of actual inflation.

\section{Summary and Concluding Remarks}

The main purpose of the present paper is to consider a number of key issues relating to how households form their inflation expectations. While how households form their inflation expectations has increasingly received recent attention, the present analysis in considering their 'anchoring' behavior brings together two important strands of the existing literature - 'inattentiveness' or the epidemiological version of the 'sticky information expectation' and the 'anchoring' on inflation targets. We empirical assess potentially competing issues. Using novel consumer-based survey data we are also able to consider the demographic nature of individuals 'anchoring' behavior when forming their inflation expectations.

The novel dataset has been used to estimate a new model encompassing both the anchoring approach, derived as part the long-run dynamics, and the Carroll epidemiological absorption mechanism in the short run. The empirical analyses consider key competing theories and propositions relating to households forming inflation expectations. Specifically, their 'anchoring' and 'absorption' behavior and how this can vary demographically. As highlighted in the introductory section, the present analysis considers two strands in the literature: the role of central bank inflation targeting and non-expert inattentiveness as they learn from experts.

Importantly, the dataset enables us to consider household expectations formation distinguishing between the aggregate and disaggregate approach. The issue of heterogeneity and disagreement amongst professional forecasts have received considerable attention recently. Likewise households vary when they form their respective inflation expectations. Hence, the present analyses show that the aggregate approach captures inadequately how households update their inflation expectations. The 
estimated aggregate dynamics find that the households' absorption rate is around 0.3 (Table 2), while the disaggregate dynamics reported in Table 4 indicate that they vary widely between 0.31 and 0.79 . Indeed, the estimated steady state solution following equation (10) vary too. The estimated aggregate dynamics give a value between 5 and $6 \%$ and between 4 and $6.5 \%$ for the demographic groups. Nevertheless, the various demographic groups, similar to the aggregate dynamics, overreact and display no significant change or structural break.

The results clearly indicate that Italian households are excessively sensitive to their perception of current inflation rates. While the long-run dynamics indicate they anchor their expectations on professional forecasts. Interestingly, while the long-run professional inflation expectations approximate the ECB targets, the household long-run expectations are considerably higher ${ }^{26}$. Households tend to set their expectations to that of the professional forecasts but at a ratio greater than one. These results are consistent with those found by Coibion and Gorodnichencko (2010) and Dovern et al (2012), which focuses on professional forecasters, where central bank independence affect 'anchoring' and 'inattentive' behaviour but not explicit inflation targeting.

The present paper also investigates the important but little explored issue of households' overreaction when updating and forming their inflation expectations. The empirical findings suggest that most households tend to overreact as they update their inflation expectations. Also, when they overreact they rarely revise their expectations, the only exceptions are the households of the university educated and those that fall in the youngest and oldest age category under consideration. By and large, the nonlinear estimates mimic the linear ones. No asymmetric overreaction was found in either regime. Hence, households that have overreactions do not distinguish between periods when they expect inflation to have an upward or downward momentum. Conversely, a number of these overreacting households tend to revise their expectations in periods where they expect inflation to have lower momentum.

The finding that inflation expectations are higher than actual inflation has already been documented in the literature for the US (van der Klauw et al., 2008). In the case of Italy, the fact that inflation expectations are higher than actual outcomes may be linked to a 'change over' effect that started in the immediate aftermath of the adoption

26 According to Issing (2008), the ECB is committed to anchor inflation expectations at a level consistent with the mandate of maintaining price stability in the Euro area as a whole; in this sense, the ECB may not be particularly interested if inflation expectations exceed its definition of price stability in an individual country. 
of the common currency and lasted for a long period thereafter (see also on this Del Giovane, Fabiani, \& Sabbatini, 2009). According to Bruine de Bruine et al. (2010), there is also the possibility that overestimation is linked to the design of the questionnaire: questions on 'price in general' or 'price you pay' are found to elicit higher expectations than those based on questions about the 'rate of inflation' (and the EU harmonised questionnaire asks about 'consumer prices', which is a concept closer to that of 'price in general' than to that of 'rate of inflation').

An interesting paradoxical finding is that households undertake the fairly costly action of 'anchoring' on professional forecasters in the long run, while professional long-run forecasts tend toward the ECB medium-term inflation target. However, is this a reflection on the ECB's credibility? Further research on this is however advisable in the future, possibly extending the analysis to other Euro area countries, exposed to the same changeover shock, but with a different tradition in the conduct of monetary policies. 


\section{References}

Akerlof, G., Dickens, W. and G. Perry. (1996) The macroeconomics of low inflation. Brookings Paper in Economic Activity No. 1: 1-76.

. (2000) Near-rational wage and price setting and the long-run Phillips curve. Brookings Paper in Economic Activity No. 1: 1-60.

Andrews, D. W. K. (1993) Tests for parameter instability and structural change with unknown change point, Econometrica, Vol. 61, No. 4: 821-856.

Ball, L.N., Mankiw, G. and R. Reis. (2005) Monetary Policy for Inattentive Economies. Journal of Monetary Economics Vol. 52: 703-725.

Beechy, M.J., Johannsen, B.J. and A.T. Levin. (2011) Are Long-run Inflation Expectations Anchored More Firmly in the Euro Area than in United States? American Economic Journal: Macroeconomics 3 (April): 104-129.

Biau O., Deiden, H., Ferrucci, G., Friz, R. and S. Linden. (2010) Consumers' quantitative inflation perceptions and expectations in the euro area: an evaluation, paper presented at the Conference on Consumer Inflation Expectations, New York Federal Reserve Bank, NY, November 16-17, 2010. Available athttp://ny.frb.org./research/conference/2010/consumer/FerrucciFRBNY.pdf

Blanchflower, D.G. and C. Mac Coille. (2009) The formation of inflation expectations: an empirical analysis for the UK, Bank of England, speech at http://www.bankofengland.co.uk/publications/speeches/2009/speech387.pdf

Bryan, M.F. and G. Venkatu. (2001a) The demographics of inflation opinion surveys. Federal Reserve Bank of Cleveland, October.

(2001b) The curiously different inflation perspectives for men and women. Federal Reserve Bank of Cleveland, November.

Bruine de Bruin, W., Manski, C.F., Topa, G. and W. Van der Klaauw. (2009) Measuring Consumer Uncertainty about Future Inflation. FRB of New York Staff Report No. 415.

Bruine de Bruin, W., Van der Klaauw, W., Downs, J.S., Fischhoff, B., Topa, G. and O. Armantier. (2010) The Effect of Question Wording on Reported Expectations and Perceptions of Inflation. FRB of New York Staff Report No. 443, April.

Carroll, C. D. (2003) Macroeconomic expectations of households and professional forecasters. The Quarterly Journal of Economics February: 269-298.

(2006) The Epidemiology of macroeconomic expectations. In The Economy as an Evolving Complex System, III, edited by L.Blume and S. Durlauf. Oxford: Oxford University Press.

Chow, G. C. (1960) Tests of equality between sets of coefficients in two linear regressions, Econometrica, Vol. 28, No. 3: 591-605.

Coibion, O and Y, Gorodnichenko (2010) Information Rigidity and the Expectations Formation Process: A Simple Framework and New Facts. NBER Working Paper No. 16537. 
Del Giovane, P., Fabiani, S., and R. Sabbatini (2009) What's behind 'inflation perceptions'? A survey-based analysis of Italian consumers Giornale degli Economisti ed Annali di Economia Vol. 68, No. 1: 1-52.

Dovern, J, U., Fritsche and J., Slacalek., 2012, Disagreement among Forecasters in G7 Countries, Review of Economics and Statistic, forthcoming.

Easaw, J. and R. Golinelli (2010) Household forming inflation expectations: active and passive absorption rates. B.E. Journal of Macroeconomics (contributions) Vol. 10. No. 1, article 35.

European Commission (2006) The joint harmonised EU programme of business and consumer surveys, European Economy, Special Report No 5.

Fuhrer, J., (2012) Real Expectations: Replacing rational expectations with survey expectations in dynamics macro models, paper presented at the International Forecasting Symposium, Boston, 24 ${ }^{\text {th }}$ to $27^{\text {th }}$ June 2012.

Gefang,D, Koop., G and Potter, S., 2012, The dynamics of UK and US inflation expectations. Computational Statistics and Data Analysis, Vol. 56: 3120-3133.

Hausman, J. A. (1978) Specification tests in econometrics. Econometrica, Vol. 46, No. 6: $1251-1271$.

Holden, K. and D. A. Peel (1990) On testing for unbiasedness and efficiency of forecasts. Manchester School Vol. 58: 120-127.

Im, K.S., Pesaran, H.M. and Y. Shin (2003) Testing for unit roots in heterogeneous panels. Journal of Econometrics Vol. 115: 53-74.

Johansen, S. (1992) Cointegration in partial systems and the efficiency of single equation analysis. Journal of Econometrics Vol. 52: 389-402.

Kelly, R. (2008) The causal relationship between inflation and inflation expectations in the UK. Bank of England Discussion Paper, No. 24.

Lanne, M, Luoma, A. and J. Luoto (2009) A naïve sticky information model of households' inflation expectations. Journal of Economic Dynamics and Control Vol. 33: 1332-1344.

Levin, A.T., Natalucci, F.M. and J.M. Piger (2004) The macroeconomic effects of Inflation targeting. Fed of St. Louis Review Vol. 86, No. 4: 51-80.

Lombardelli, C. and J. Saleheen (2003) Public expectations of UK inflation. Bank of England Quarterly Bulletin Autumn.

Malgarini, M. (2009) Quantitative inflation perceptions and expectations of Italian consumers. Giornale degli Economisti e Annali di Economia Vol. 68, No. 1: 5380 .

Malgarini, M., Pugno, M. and G. Zezza (2009) Life satisfaction in Italy: evidence from the ISAE consumers survey. ISAE Working Paper, No. 121.

Mankiw, N.G. and R. Reis (2002) Sticky Information Versus Sticky Prices: A Proposal to Replace the New Keynesian Phillips Curve. The Quarterly Journal of Economics Vol. 117: 1295-1328.

(2007) Sticky Information in General Equilibrium. Journal of the European Economic Association Vol. 5: 603-613. 
Mankiw, N.G., Reis, R. and J. Wolfers (2004) Disagreement about Inflation Expectations. NBER Macroeconomics Annual 2003 Vol. 18: 209-270.

Newey, W.K. and K.D. West (1987) A simple positive semi-definite heteroskedasticity and autocorrelation-consistent covariance matrix. Econometrica Vol. 55: 703-708.

Pesaran, M.H., Shin, Y. and R.P. Smith (2001) Bounds testing approaches to the analysis of long run relationships. Journal of Applied Econometrics Vol. 16: 289326.

Pesaran, M.H., Shin, Y. and R.P. Smith (1999) Pooled mean group estimation of dynamic heterogeneous panels. Journal of the American Statistical Association Vol. 94, No. 446: 621-634.

Reis, R. (2006a) Inattentive consumers. Journal of Monetary Economics Vol. 53: 17611800.

(2006b) Inattentive producers. Review of Economic Studies Vol. 73: 793-821.

Scheller, H. K. (2006) The ECB: History, Role, and Functions. Frankfurt: European Central Bank. Available at:

http://www.ecb.int/pub/pdf/other/ecbhistoryrolefunctions2006en.pdf

Van der Klaauw, W., Bruine de Bruin, W., Topa, G., Potter, S. and M.F. Bryan (2008) Rethinking the Measurement of Household Inflation Expectations: Preliminary Findings. FRB of New York Staff Report No. 359, December. Verbeek, M. and T. Nijman (1992) Can cohort data be treated as genuine panel data? Empirical Economics Vol. 17, No. 1: 9-23.

White, H. (1980) A heteroskedastic-consistent covariance matrix estimator and a direct test for heteroskedasticity. Econometrica Vol. 48: 817-838. 


\section{Appendix A1: Households Inflation Expectations Over-reaction and Revision: Definition and Tests}

Starting with equation (5), where we assume for simplicity that $\phi_{2}=\phi_{3}=0$ (i.e. we exclude the role of actual and perceived inflation in the long run, as also emerges from our empirical application), we can re-write the model in terms of households' and forecasters' expected inflation levels as follows:

$$
E_{t}^{h}\left(\pi_{t+1}\right)=\lambda_{11} E_{t}^{F}\left(\pi_{t+1}\right)-\left(\lambda_{11}+\lambda_{2} \phi_{1}\right) E_{t-1}^{F}\left(\pi_{t}\right)+\left(1+\lambda_{2}\right) E_{t-1}^{h}\left(\pi_{t}\right)+u_{t}
$$

where, $u_{t}=\lambda_{12} \Delta \pi_{t}^{P, h}+\lambda_{13} \Delta \pi_{t-1}-\lambda_{2} \phi_{4} \pi^{T}+\varepsilon_{t}$. Also if : $\lambda_{11}+\lambda_{2} \phi_{1}=0$, i.e. if $\lambda_{2}=-\frac{\lambda_{11}}{\phi_{1}}$ the second term in equation (A.1) collapses to:

$$
E_{t}^{h}\left(\pi_{t+1}\right)=\lambda_{11} E_{t}^{F}\left(\pi_{t+1}\right)+\left(1-\frac{\lambda_{11}}{\phi_{1}}\right) E_{t-1}^{h}\left(\pi_{t}\right)+u_{t}
$$

and also if the long-run effect of forecasters' predictions on households' inflation expectations is one $\left(\phi_{1}=1\right)$, we have in equation (A.2) is a slightly more complex version of the Carroll epidemiological model (denoted by equation (1) in the main text) because of $u_{t}=\lambda_{12} \Delta \pi_{t}^{P, h}+\lambda_{13} \Delta \pi_{t-1}-\lambda_{2} \phi_{4} \pi^{T}+\varepsilon_{t}$, i.e. the presence in $u_{t}$ of effects due to short-run fluctuations/changes in the perceived and actual inflation, and a constant term related to anchoring on the Central Bank target.

If we write equation (A.1) in order to explicit $-\lambda_{2}$, i.e. the share of households informed by professional forecasters, we have that; ${ }^{27}$

$$
E_{t}^{h}\left(\pi_{t+1}\right)=-\lambda_{2} \frac{\lambda_{11} E_{t}^{F}\left(\pi_{t+1}\right)-\left(\lambda_{11}+\lambda_{2} \phi_{1}\right) E_{t-1}^{F}\left(\pi_{t}\right)}{-\lambda_{2}}+\left(1+\lambda_{2}\right) E_{t-1}^{h}\left(\pi_{t}\right)+u_{t}
$$

For ease of comparison with Carroll's epidemiological model as depicted by equation (1), we can denote the absorption rate as $\lambda=-\lambda_{2}$, and re-write equation (A.3) as: 
$E_{t}^{h}\left(\pi_{t+1}\right)=\lambda\left[\frac{\lambda_{11}}{-\lambda_{2}} E_{t}^{F}\left(\pi_{t+1}\right)+\left(\frac{\lambda_{11}}{\lambda_{2}}+\phi_{1}\right) E_{t-1}^{F}\left(\pi_{t}\right)\right]+(1-\lambda) E_{t-1}^{h}\left(\pi_{t}\right)+u_{t}$

again, if $\lambda_{2}=-\frac{\lambda_{11}}{\phi_{1}}$ and $\phi_{1}=1$, equation (A.4) collapses to Carroll's in equation (1), apart from the $u_{t}$ term (which basically captures the short-run dynamics).

\section{A1.1 - Two examples from the applied literature}

In Carroll (2003), we have that $\lambda=-\lambda_{2}=\lambda_{11}=0.3$ and $\phi_{1}=1$, therefore model (A.4) is:

$$
E_{t}^{h}\left(\pi_{t+1}\right)=0.3\left[\frac{0.3}{0.3} E_{t}^{F}\left(\pi_{t+1}\right)+\left(\frac{0.3}{-0.3}+1\right) E_{t-1}^{F}\left(\pi_{t}\right)\right]+0.7 E_{t-1}^{h}\left(\pi_{t}\right)+\hat{u}_{t}
$$

while in Easaw and Golinelli (2010), for $h=g p$ and $F=b e$, we have that $\lambda_{2}=-0.4$; $\lambda_{11}=0.7$; and $\phi_{1}=1.2$; therefore model (A.4) is:

$E_{t}^{h}\left(\pi_{t+1}\right)=0.4\left[\frac{0.7}{0.4} E_{t}^{F}\left(\pi_{t+1}\right)+\left(\frac{0.7}{-0.4}+1.2\right) E_{t-1}^{F}\left(\pi_{t}\right)\right]+0.6 E_{t-1}^{h}\left(\pi_{t}\right)+\hat{u}_{t}$

which respectively simplify to:

$E_{t}^{h}\left(\pi_{t+1}\right)=0.3 E_{t}^{F}\left(\pi_{t+1}\right)+0.7 E_{t-1}^{h}\left(\pi_{t}\right)+\hat{u}_{t}$

and to:

$E_{t}^{h}\left(\pi_{t+1}\right)=0.4\left[1.75 E_{t}^{F}\left(\pi_{t+1}\right)-0.55 E_{t-1}^{F}\left(\pi_{t}\right)\right]+0.6 E_{t-1}^{h}\left(\pi_{t}\right)+\hat{u}_{t}$

Extending Carroll's epidemiological model, Easaw and Golinelli (2010) estimated dynamics depicts a short-term overreaction of general public inflation expectations to business economists' forecasts, as their point estimates $\frac{\hat{\lambda}_{11}}{-\hat{\lambda}_{2}}>1$, i.e. $\hat{\lambda}_{11}>-\hat{\lambda}_{2}$ and $\frac{\hat{\lambda}_{11}}{-\hat{\lambda}_{2}}>\hat{\phi}_{1}$. However, as investigating overreaction was beyond the scope of the paper, they did not formally test for restrictions in the population. 


\section{A1.2 - A general statement}

Starting from our equation (4) and given the restrictions supported by our empirical outcomes that $\phi_{2}=\phi_{3}=0$ (i.e. that the steady state household expectations are only driven by professional forecasts, see equation A.1), we have expectations made by informed households overreacting to professional forecasts in $t$ for $t+1$ (in short, 'overreaction to the news in $\mathrm{t}$ ') if the null hypothesis: $\mathrm{H}_{0}: \lambda_{11}=-\lambda_{2}$ is rejected against the alternative $\mathrm{H}_{1}: \lambda_{11}>-\lambda_{2}$. Concurrently, the same households adjust their overreaction on the basis of the past month's professional forecasts in $t-1$ for $t$ ('overreaction revision through the news in $t-1$ ') if the null hypothesis: $\mathrm{H}_{\mathrm{o}} \frac{\lambda_{11}}{-\lambda_{2}}=\phi_{1}$ is rejected against the alternative $\mathrm{H}_{1}: \frac{\lambda_{11}}{-\lambda_{2}}>\phi_{1}$.

These tests can be easily computed as combinations of equation (4) parameter estimates. Under the assumptions of overreaction $\left(\lambda_{11}>-\lambda_{2}\right)$ and positive $\phi_{1}$, the overreaction revision is in absolute value smaller than the overreaction and, as soon as $\phi_{1}$ goes beyond one, the overshot revision reverts to zero (when $\frac{\lambda_{11}}{-\lambda_{2}}=\phi_{1}$ ). ${ }^{28}$

\section{Appendix A2: Consensus inflation forecast estimate and analysis}

\section{A2.1 - Estimation.}

Since 1999, we collected the annual forecasts of the inflation rate — denoted as: $E_{t, r}^{F} \dot{p}_{t+h}$ and measured on the basis of the monthly consumer price index, CPI - for the current year (partially known at the time the forecast is made) and for the following year (i.e. $h=0,1$ ) of five different forecast institutes $F$, i.e. professional forecasters. ${ }^{29}$ Such forecasts are reported and largely commented in the press at month $r$ of year $t$ in which

\footnotetext{
28 For even larger $\phi_{1}$ estimates (i.e. when $\lambda_{11} /-\lambda_{2}<\phi_{1}$ ), the overshot revision becomes a further overreaction based on past professional forecasts

29 The five professional forecasters are three Italian institutes (Ricerche per l'Economia e la Finanza, Associazione Prometeia per le Previsioni Econometriche, and Istituto di Studi e Analisi Economica), and two international organizations (IMF's World Economic Outlook, and OECD's Economic Outlook). They are respectively labeled as $F=$ ref, pro, isae, weo, and eco.
} 
they are published. ${ }^{30}$ In this way, the institutes' forecasts are (intermittently) published only for some months $r$ of each year $t$, while the ISAE household survey is regularly conducted each month $m$.

In order to obtain monthly series of professional forecasts, in the month when the forecast of the $F^{t h}$ institute is published (i.e. $m=r$ ), we assume that the inflation forecast over the next twelve months is given by the weighted average of current- and next-year inflation forecasts:

$$
E_{t}^{F}\left(\pi_{t+1}\right)=\frac{12-m}{12} E_{t, r}^{f} \dot{p}_{t}+\frac{m}{12} E_{t, r}^{f} \dot{p}_{t+1}
$$

The two weights for $t$ and $t+1$ forecasts are respectively proportional to the number of months from $m$ to the end of the current year, and to the remaining months of the following year. If in the following month the $F^{\text {th }}$ institute does not publish a new forecast, the $F$ monthly prediction in $m+1$ is assumed to be equal to the most recent forecasts for $t$ and $t+1\left(E_{t, r}^{F} \dot{p}_{t+h}\right)$ averaged with updated weights: $\frac{12-m-1}{12}$ and $\frac{m+1}{12}$ ; note that weights always sum to one.

Though the five forecasts broadly tend to follow a similar path over time, over the sample period there are more 'noisy' periods in which the professional forecasters tend to disagree to a larger extent.

In order to compute a monthly consensus series, we take the average of the five institutes' forecasts, and we define the series of the monthly standard deviation of the five forecasts as the 'noise' that might mix up the forecast signal.

The time series of the consensus inflation forecasts witnesses a rapid increase from the end of 2007 to the first half of 2008, then rapidly drops to about $1 \%$ during 2009. Regarding noise, we note that the institutes' disagreements peaked during the last period of the sample, i.e. when the inflation forecasts started to move away from the 2$2.3 \%$ range typical of the first part of the sample.

$30 \quad$ With few exceptions, $r$ ef and pro publish their forecasts four times per year (i.e. $r=$ January or February, April or May, September or October, and December), while the other three institutes report the inflation forecasts twice per year: $r=$ February and May for isae, $r=$ April and October for weo, and $r=$ June and December for eco. 


\section{A2.2 - Test for consensus bias and weak form of informational efficiency.}

If we denote 12-months ahead inflation consensus forecasts in $t$ as $y_{t+12 \mid t}$, and the corresponding actual inflation realizations as $y_{t+12}$, tests of consensus rationality can be based on the regression equation:

$$
y_{t+12}=\alpha+\beta y_{t+12 \mid t}+\varepsilon_{t+12}
$$

where $\mathrm{H}_{0}: \alpha=0, \beta=1$ entails unbiasedness/weak rationality. A consistent estimate of the covariance matrix of $\alpha$ and $\beta$ parameters is given by Newey and West (1987) heteroskedasticity and autocorrelation corrected (HAC) standard errors.

Alternatively, as noted in Holden and Peel (1990), another way to test for unbiasedness is via the test $\mathrm{H}_{0}: \alpha=0$ in the regression:

$$
e_{t+12 \mid t}=y_{t+12}-y_{t+12 \mid t}=\alpha+\varepsilon_{t+12}
$$

Regression results clearly stress the unbiasedness/weak rationality of our consensus series (with $\mathrm{H}_{0}$ p-values which are always above 15\%). This outcome is robust to the use of alternative measures of inflation (either y-o-y or annualized m-o-m rates of growth computed from either the Italian index of consumer prices or the Italian HICP, both series are released by the Italian National Statistics Agency), to the model on which inferences are based (see above), and to the use of HAC or bootstrapped standard errors. Details are available upon request.

\section{A2.3 - Consensus univariate representation.}

If consensus inflation forecasts can be represented by the stationary p-order auto-regressive model: $E_{t}^{F}\left(\pi_{t+1}\right)=\beta_{0}+\sum_{k=1}^{p} \beta_{k} E_{t-k}^{F}\left(\pi_{t-k+1}\right)+v_{t}$, they collapse to the long-run steady state scalar solution: $E^{F}\left(\pi^{*}\right)=\beta_{0} /\left(1-\sum_{k=1}^{p} \beta_{k}\right)$.

In order to test for stationarity of the $E_{t}^{F}\left(\pi_{t+1}\right)$ univariate representation, we used both informal (time plots, correlogram) and formal (various unit root/stationarity tests) techniques. Given that all results pointed to consensus series stationarity, we estimated over the 2002m6-2010m12 period the best univariate model for consensus forecasts as the following restricted AR(5) representation (standard errors in brackets): 


$$
\begin{aligned}
E_{t}^{F}\left(\pi_{t+1}\right)= & 0.145+1.087 E_{t-1}^{F}\left(\pi_{t}\right)-0.163 E_{t-5}^{F}\left(\pi_{t-4}\right)+\hat{\varepsilon}_{t} \\
& (0.050)(0.035)
\end{aligned}
$$

where, on the basis of a number of misspecification tests, residuals $\hat{\varepsilon}_{t}$ are a valid representation of a normal white noise process. On the basis of these estimates, the steady state solution of consensus is $E^{F}\left(\pi^{*}\right)=1.924$, and the corresponding $95 \%$ confidence interval ranges between 1.705 and 2.142, which denotes professional forecasts for Italy which are broadly consistent with the ECB $2 \%$ reference rate for the whole Euro area inflation. 
Tab. 1

Expected inflation: sample composition and statistics by selected characteristics

\# obs. \% share mean std. dev. \% points deviation from
(1)
(2)
(3)
(4)
$(5)^{\mathrm{c}}$
(6) ${ }^{\mathrm{d}}$

reference group ${ }^{\mathrm{a}, \mathrm{b}}$

Employment

- self-employed

$\begin{array}{rr}11398 & 8.8 \\ 32715 & 25.3 \\ 12859 & 10.0 \\ 36448 & 28.2 \\ 35792 & 27.7\end{array}$

$4.4 \quad 10.6$

- white collar

$5.4 \quad 11.9$

- blue collar

$6.3 \quad 13.7$

- pensioner

4.7

11.2

- other ${ }^{\mathrm{e}}$

$5.9 \quad 13.5$

$\begin{array}{ll}-1.058^{* * *} & -1.002^{* * *} \\ 0.527^{* * *} & 0.519^{* * *} \\ 0.152^{* *} & 0.216^{*} \\ 0.264^{* *} & 0.284^{* *}\end{array}$

Education

- university

13653

10.6

$4.7 \quad 10.6$

$-0.378^{* * *}-0.256^{* *}$

- upper-secondary

50697

39.2

5.3

12.0

- lower-secondary

39510

30.6

$5.7 \quad 12.8$

- elementary

25352

19.6

$5.3 \quad 12.7$

$0.591^{* * *} \quad 0.564^{* * * *}{ }^{* * *}$

Gender

- male

- female

64527

49.9

$5.0 \quad 11.4$

64685

50.1

$5.7 \quad 13.0$

$0.463^{* * *}$

$0.487^{* * *}$

Age

$-<30$

11998

9.3

44700

34.6

6.1

13.9

0.167

0.064

$-30-49$

37639

29.1

$-50-64$

34875

$5.8 \quad 12.8$

$5.3 \quad 12.1$

$0.918^{* * *} \quad 0.877^{* * *}$

- > 64

27.0

$4.6 \quad 11.0$

$-0.759^{* * *}-0.658^{* * *}$

Full sample

$129212 \quad 100.0$

5.4

12.3

$-1.898$

$-1.664$

( $\left.{ }^{a}\right)$ The reference group is: white-collar employee, upper-secondary educated, male, and aged 30-49.

( ${ }^{\text {b }) * * *}$ and ${ }^{* *}$ respectively denote $1 \%$ and $5 \%$ significant differences. Parameters' standard errors are robust to heteroschedasticity, see White (1980).

(c) OLS estimates of $\alpha_{k}$ in the model: $E_{t}^{h}\left(\pi_{t+1}\right)=\alpha_{0}+\alpha_{k} D(k)_{t}^{h}+\varepsilon_{t}^{h}$, where $\alpha_{0}$ is the average expected inflation rate for the reference group (equal to 5.452, as shown in the last row of column 5), and $\alpha_{k}$ are the deviations to $\alpha_{0}$ due to the $k$ individual characteristics listed along the rows (measured by the $k$ dummy variables $D(k)$ ).

( $\left.{ }^{\mathrm{d}}\right)$ OLS estimates of $\alpha_{k}$ in the model: $E_{t}^{h}\left(\pi_{t+1}\right)=\alpha_{t} \tau_{t}+\alpha_{k} D(k)_{t}^{h}+\varepsilon_{t}^{h}$, where previous intercept $\alpha_{0}$ is substituted by the time effects $\alpha_{t}$ (whose average over time estimate is 5.424, as shown in the last row of column 6) multiplied by $\tau_{t}$ which is a dummy variable equal to 1 if the observation is in $t$, zero otherwise.

(e) Unemployed, student or housewife. 
Tab. 2

Main outcomes from estimating three alternative models for repeated cross-sections

Model with: ${ }^{\text {a }}$

only individual

characteristics plus time effects

0.0000

0.0000

0.0000

0.0000

0.0000

0.0000

0.0000

0.0005

0.0709

0.2100 plus perceived inflation, consensus, and interactions

all time effects, i.e. $\alpha_{t}=0 \forall t$

0.0000

0.0000

interaction of individual characteristics with

perceived inflation, overall i.e.

$\alpha_{P}=\alpha_{P k}=0 \forall k$

of which: $\forall k \in c$, and $c=$

- employment

- education

- gender

- age

consensus forecast, overall

i.e. $\alpha_{F}=\alpha_{F k}=0 \forall k$

of which: $\forall k \in c$, and $c=$

- employment

- education

- gender

0.1273

- age

0.4804

$\mathrm{R}^{2}$

0.0049

0.1837

0.2994

\# of parameters

12

104

128

$\left({ }^{a}\right.$ ) Model (5) results in the first column are the same as those reported in column (5) of Table 1; model (6) results in the second column are the same as those reported in column (6) of Table 1 . The third column reports results from model (7), which is:

$E_{t}^{h}\left(\pi_{t+1}\right)=\alpha_{t} \tau_{t}+\alpha_{k} D(k)_{t}^{h}+\alpha_{P} \pi_{t}^{P, h}+\alpha_{F} E_{t}^{F}\left(\pi_{t+1}\right)+$ $\alpha_{P k}\left[D(k)_{t}^{h} \times \pi_{t}^{P, h}\right]+\alpha_{F k}\left[D(k)_{t}^{h} \times E_{t}^{F}\left(\pi_{t+1}\right)\right]+\varepsilon_{t}^{h}$

(b) Inferences are robust to heteroskedasticity, see White (1980). 
Tab 3

Dynamic modelling of average households expectations $(T=92)^{a}$

\begin{tabular}{|c|c|c|c|c|c|}
\hline & (1) & (2) & (3) & (4) & (5) \\
\hline$\lambda_{11}$ & $\begin{array}{r}2.1677 \\
1.114 \\
1.95\end{array}$ & $\begin{array}{r}3.1542 \\
1.125 \\
2.80\end{array}$ & $\begin{array}{r}2.8565 \\
0.997 \\
2.87\end{array}$ & $\begin{array}{r}2.8825 \\
0.990 \\
2.91\end{array}$ & $\begin{array}{r}2.7312 \\
0.971 \\
2.81\end{array}$ \\
\hline$\lambda_{12}$ & $\begin{array}{r}0.2006 \\
0.045 \\
4.49\end{array}$ & $\begin{array}{r}0.2073 \\
0.045 \\
4.58\end{array}$ & $\begin{array}{r}0.2052 \\
0.045 \\
4.58\end{array}$ & $\begin{array}{r}0.2015 \\
0.044 \\
4.60\end{array}$ & $\begin{array}{r}0.2032 \\
0.044 \\
4.65\end{array}$ \\
\hline$\lambda_{13}$ & $\begin{array}{r}0.0087 \\
0.048 \\
0.18\end{array}$ & $\begin{array}{r}-0.0996 \\
0.413 \\
-0.24\end{array}$ & & & \\
\hline$\lambda_{2}$ & $\begin{array}{r}-0.3200 \\
0.072 \\
-4.44\end{array}$ & $\begin{array}{r}-0.3218 \\
0.075 \\
-4.28\end{array}$ & $\begin{array}{r}-0.3117 \\
0.072 \\
-4.31\end{array}$ & $\begin{array}{r}-0.3055 \\
0.071 \\
-4.33\end{array}$ & $\begin{array}{r}-0.2824 \\
0.065 \\
-4.38\end{array}$ \\
\hline$\phi_{1}$ & $\begin{array}{r}2.8094 \\
1.120 \\
2.51\end{array}$ & $\begin{array}{r}2.1066 \\
1.269 \\
1.66\end{array}$ & $\begin{array}{r}3.1869 \\
1.124 \\
2.83\end{array}$ & $\begin{array}{r}3.5405 \\
0.795 \\
4.45\end{array}$ & $\begin{array}{r}2.8630 \\
0.154 \\
18.58\end{array}$ \\
\hline$\phi_{2}$ & $\begin{array}{r}0.0192 \\
0.047 \\
0.41\end{array}$ & $\begin{array}{r}0.0129 \\
0.048 \\
0.27\end{array}$ & $\begin{array}{r}0.0215 \\
0.048 \\
0.45\end{array}$ & & \\
\hline$\phi_{3}$ & $\begin{array}{r}0.2869 \\
0.206 \\
1.39\end{array}$ & $\begin{array}{r}0.6267 \\
0.817 \\
0.77\end{array}$ & & & \\
\hline$\phi_{4} \pi^{T}$ & $\begin{array}{r}-0.9187 \\
1.648 \\
-0.56\end{array}$ & $\begin{array}{r}-0.1897 \\
2.121 \\
-0.09\end{array}$ & $\begin{array}{r}-1.0978 \\
1.690 \\
-0.65\end{array}$ & $\begin{array}{r}-1.3724 \\
1.585 \\
-0.87\end{array}$ & \\
\hline $\begin{array}{l}\mathrm{R}^{2} \\
\text { RMSE }\end{array}$ & $\begin{array}{l}0.38291 \\
0.82415\end{array}$ & $\begin{array}{l}0.36730 \\
0.83451\end{array}$ & $\begin{array}{l}0.361 \\
0.829\end{array}$ & $\begin{array}{l}0.359 \\
0.825\end{array}$ & $\begin{array}{l}0.355 \\
0.824\end{array}$ \\
\hline $\begin{array}{l}\text { Testing for the abse } \\
\text { - overreaction } \\
\text { - overshot revision }\end{array}$ & $\begin{array}{l}0.034 \\
0.268\end{array}$ & $\begin{array}{l}0.012 \\
0.062\end{array}$ & $\begin{array}{l}0.009 \\
0.091\end{array}$ & $\begin{array}{l}0.008 \\
0.099\end{array}$ & $\begin{array}{l}0.011 \\
0.072\end{array}$ \\
\hline $\begin{array}{l}\text { Long-run solution c } \\
\text { - upper-bound } \\
\text { - lower bound }\end{array}$ & dinflation & & & $\begin{array}{l}6.20 \\
4.67\end{array}$ & $\begin{array}{l}6.13 \\
4.89\end{array}$ \\
\hline
\end{tabular}

where regressors respectively measure changes in: professional forecasts, perceived and actual inflation rates; lagged levels of: average households expectations, professional forecasts, perceived and actual inflation rates; standard errors are below each estimate and, below standard errors, the t-statistics. In column (1) the actual inflation rate is measured by the annualised m-o-m growth of CPI, in column (2) by the y-o-y growth of HICP.

( $\left.{ }^{b}\right)$ P-values of Ho: $\lambda_{11}=-\lambda_{2}$, and Ho: $\lambda_{11} /-\lambda_{2}=\phi_{1}$ respectively.

(c) Defined as: $E^{M}\left(\pi^{*}\right)=\phi_{1} E^{F}\left(\pi^{*}\right)+\phi_{4} \pi^{T}$; the consensus $95 \%$ confidence interval goes from $1.7 \%$ to $2.1 \%$. 
Tab 4

Alternative group definitions ${ }^{\mathrm{a}}$

\begin{tabular}{|c|c|c|c|c|}
\hline & Male & Female & Working & Not working \\
\hline & \multicolumn{2}{|c|}{ panel \# 2} & \multicolumn{2}{|c|}{ panel \# 1} \\
\hline University & $1(5.1)$ & $2(4.4)$ & $1(6.8)$ & $2(2.7)$ \\
\hline Upper-secondary & $3(19.2)$ & $4(16.9)$ & $3(21.7)$ & $4(14.4)$ \\
\hline Lower-secondary & $5(15.3)$ & $6(15.3)$ & $5(10.6)$ & $6(20.0)$ \\
\hline Elementary & $7(8.4)$ & 8 (15.5) & & 23.9) \\
\hline \multicolumn{5}{|c|}{ panel \# 3} \\
\hline Self-employed & $1(5.8)$ & $2(2.3)$ & & \\
\hline White collar & $3(12.7)$ & $4(10.2)$ & & \\
\hline Blue collar & $5(6.5)$ & $6(3.2)$ & & \\
\hline Pensioner & 7 (18.6) & $8(12.1)$ & & \\
\hline Other $^{\mathrm{b}}$ & $9(4.4)$ & $10(24.4)$ & & \\
\hline \multicolumn{5}{|c|}{ panel \# 4} \\
\hline Age $<30$ & $1(4.4)$ & $5(3.7)$ & & \\
\hline $30-49$ & $2(15.4)$ & $6(16.6)$ & & \\
\hline $50-64$ & $3(14.0)$ & $7(14.9)$ & & \\
\hline$>64$ & $4(14.3)$ & $8(16.8)$ & & \\
\hline
\end{tabular}

$\left({ }^{a}\right)$ For each panel, the number that labels each group is reported together with, in brackets, the \% frequency of the group on the total surveyed people. The sum of \% frequencies by panel may be not exactly equal to 100 for rounding effects.

(b) Unemployed, student or housewife. 
Tab 5 - Main estimation results, pseudo panel \# $1^{\mathrm{a}}$

\begin{tabular}{|c|c|c|c|c|c|c|c|}
\hline groups: ${ }^{a}$ & 1 & 2 & 3 & 4 & 5 & 6 & 7 \\
\hline \multicolumn{8}{|l|}{ Unrestricted model $^{\mathrm{b}}$} \\
\hline $\begin{array}{r}\lambda_{2}^{h} \\
t\end{array}$ & $\begin{array}{r}-0.6643 \\
-7.13\end{array}$ & $\begin{array}{r}-0.8032 \\
-7.71\end{array}$ & $\begin{array}{r}-0.4345 \\
-5.03\end{array}$ & $\begin{array}{r}-0.5341 \\
-5.64\end{array}$ & $\begin{array}{r}-0.6178 \\
-6.31\end{array}$ & $\begin{array}{r}-0.3249 \\
-4.18\end{array}$ & $\begin{array}{r}-0.3291 \\
-4.27\end{array}$ \\
\hline$\phi_{2}^{h}=\phi_{3}^{h}=0^{c}$ & $\begin{array}{l}0.2955 \\
0.2989\end{array}$ & $\begin{array}{l}0.2201 \\
0.3394\end{array}$ & $\begin{array}{l}0.0355 \\
0.5424\end{array}$ & $\begin{array}{l}0.1502 \\
0.1484\end{array}$ & $\begin{array}{l}0.4904 \\
0.9068\end{array}$ & $\begin{array}{l}0.7906 \\
0.2729\end{array}$ & $\begin{array}{l}0.7850 \\
0.9389\end{array}$ \\
\hline$\lambda_{13}^{h}=0^{c}$ & $\begin{array}{l}0.6530 \\
0.9551\end{array}$ & $\begin{array}{l}0.8533 \\
0.2055\end{array}$ & $\begin{array}{l}0.0752 \\
0.3738\end{array}$ & $\begin{array}{l}0.7057 \\
0.2894\end{array}$ & $\begin{array}{l}0.4005 \\
0.7460\end{array}$ & $\begin{array}{l}0.1963 \\
0.0650\end{array}$ & $\begin{array}{l}0.3161 \\
0.0284\end{array}$ \\
\hline$\lambda_{13}^{h}=\phi_{2}^{h}=\phi_{3}^{h}=0^{c}$ & $\begin{array}{l}0.1206 \\
0.4041\end{array}$ & $\begin{array}{l}0.1568 \\
0.3642\end{array}$ & $\begin{array}{l}0.0788 \\
0.6533\end{array}$ & $\begin{array}{l}0.2676 \\
0.2471\end{array}$ & $\begin{array}{l}0.1238 \\
0.9211\end{array}$ & $\begin{array}{l}0.6044 \\
0.2220\end{array}$ & $\begin{array}{l}0.5221 \\
0.0515\end{array}$ \\
\hline \multicolumn{8}{|l|}{ Restricted model } \\
\hline $\begin{array}{c}\lambda_{11}^{h} \\
t\end{array}$ & $\begin{array}{r}5.5517 \\
3.77\end{array}$ & $\begin{array}{r}4.6485 \\
1.77\end{array}$ & $\begin{array}{r}2.0755 \\
1.52\end{array}$ & $\begin{array}{r}4.6952 \\
3.33\end{array}$ & $\begin{array}{r}4.8189 \\
2.63\end{array}$ & $\begin{array}{r}3.4988 \\
2.54\end{array}$ & $\begin{array}{r}3.7012 \\
2.68\end{array}$ \\
\hline $\begin{array}{c}\lambda_{12}^{h} \\
t\end{array}$ & $\begin{array}{r}0.2066 \\
5.46\end{array}$ & $\begin{array}{r}0.2201 \\
4.83\end{array}$ & $\begin{array}{r}0.2372 \\
5.34\end{array}$ & $\begin{array}{r}0.1028 \\
2.12\end{array}$ & $\begin{array}{r}0.1621 \\
3.25\end{array}$ & $\begin{array}{r}0.2069 \\
4.17\end{array}$ & $\begin{array}{r}0.1281 \\
3.42\end{array}$ \\
\hline $\begin{array}{r}\lambda_{2}^{h} \\
t\end{array}$ & $\begin{array}{r}-0.6573 \\
-6.99\end{array}$ & $\begin{array}{r}-0.7929 \\
-7.60\end{array}$ & $\begin{array}{r}-0.3828 \\
-4.49\end{array}$ & $\begin{array}{r}-0.4888 \\
-5.31\end{array}$ & $\begin{array}{r}-0.6322 \\
-6.47\end{array}$ & $\begin{array}{r}-0.3301 \\
-4.33\end{array}$ & $\begin{array}{r}-0.3176 \\
-4.30\end{array}$ \\
\hline $\begin{array}{r}\phi_{1}^{h} \\
t\end{array}$ & $\begin{array}{r}2.8307 \\
5.30\end{array}$ & $\begin{array}{r}3.0840 \\
3.91\end{array}$ & $\begin{array}{r}3.5932 \\
4.29\end{array}$ & $\begin{array}{r}3.4826 \\
4.97\end{array}$ & $\begin{array}{r}4.1416 \\
5.95\end{array}$ & $\begin{array}{r}4.2942 \\
4.21\end{array}$ & $\begin{array}{r}3.9917 \\
3.68\end{array}$ \\
\hline $\begin{array}{c}\phi_{4}^{h} \pi^{T} \mathrm{~d} \\
t\end{array}$ & $\begin{array}{r}-0.5312 \\
-0.50\end{array}$ & $\begin{array}{r}-1.2939 \\
-0.82\end{array}$ & $\begin{array}{r}-1.6324 \\
-0.98\end{array}$ & $\begin{array}{r}-1.4187 \\
-1.02\end{array}$ & $\begin{array}{r}-2.1652 \\
-1.56\end{array}$ & $\begin{array}{r}-2.6008 \\
-1.28\end{array}$ & $\begin{array}{r}-2.2547 \\
-1.05\end{array}$ \\
\hline $\mathrm{R}^{2}$ & 0.5285 & 0.5725 & 0.4053 & 0.3065 & 0.4043 & 0.3947 & 0.3182 \\
\hline $\begin{array}{l}\text { Andrews break } \\
\text { Chow break }\end{array}$ & $\begin{array}{l}0.0440 \\
0.0953\end{array}$ & $\begin{array}{l}0.4977 \\
0.2252\end{array}$ & $\begin{array}{l}0.1059 \\
0.2646\end{array}$ & $\begin{array}{l}0.2340 \\
0.6550\end{array}$ & $\begin{array}{l}0.0295 \\
0.0657\end{array}$ & $\begin{array}{l}0.0812 \\
0.0621\end{array}$ & $\begin{array}{l}0.2824 \\
0.2775\end{array}$ \\
\hline$\phi_{1}^{h}=\phi_{1}$ & 0.7286 & & & & & & \\
\hline \multicolumn{8}{|l|}{$P M G$ model } \\
\hline $\begin{array}{c}\lambda_{11}^{h} \\
t\end{array}$ & $\begin{array}{r}5.7210 \\
3.98\end{array}$ & $\begin{array}{r}4.7702 \\
1.88\end{array}$ & $\begin{array}{r}2.0290 \\
1.55\end{array}$ & $\begin{array}{r}4.6832 \\
3.45\end{array}$ & $\begin{array}{r}4.5122 \\
2.55\end{array}$ & $\begin{array}{r}3.3527 \\
2.52\end{array}$ & $\begin{array}{r}3.6159 \\
2.70\end{array}$ \\
\hline $\begin{array}{c}\lambda_{12}^{h} \\
t\end{array}$ & $\begin{array}{r}0.2058 \\
5.55\end{array}$ & $\begin{array}{r}0.2203 \\
4.97\end{array}$ & $\begin{array}{r}0.2376 \\
5.51\end{array}$ & $\begin{array}{r}0.1029 \\
2.18\end{array}$ & $\begin{array}{r}0.1638 \\
3.35\end{array}$ & $\begin{array}{r}0.2106 \\
4.36\end{array}$ & $\begin{array}{r}0.1292 \\
3.55\end{array}$ \\
\hline $\begin{array}{r}\lambda_{2}^{h} \\
t\end{array}$ & $\begin{array}{r}-0.6567 \\
-7.12\end{array}$ & $\begin{array}{r}-0.7929 \\
-7.80\end{array}$ & $\begin{array}{r}-0.3792 \\
-4.70\end{array}$ & $\begin{array}{r}-0.4880 \\
-5.51\end{array}$ & $\begin{array}{r}-0.6077 \\
-6.55\end{array}$ & $\begin{array}{r}-0.3123 \\
-4.37\end{array}$ & $\begin{array}{r}-0.3106 \\
-4.40\end{array}$ \\
\hline $\begin{array}{r}\phi_{1} \\
t\end{array}$ & $\begin{array}{r}3.4425 \\
12.21\end{array}$ & $\begin{array}{r}3.4425 \\
12.21\end{array}$ & $\begin{array}{r}3.4425 \\
12.21\end{array}$ & $\begin{array}{r}3.4425 \\
12.21\end{array}$ & $\begin{array}{r}3.4425 \\
12.21\end{array}$ & $\begin{array}{r}3.4425 \\
12.21\end{array}$ & $\begin{array}{r}3.4425 \\
12.21\end{array}$ \\
\hline $\begin{array}{c}\phi_{4}^{h} \pi^{T} \text { e } \\
t\end{array}$ & $\begin{array}{r}-1.7268 \\
-2.96\end{array}$ & $\begin{array}{r}-1.9943 \\
-3.23\end{array}$ & $\begin{array}{r}-1.3376 \\
-2.14\end{array}$ & $\begin{array}{r}-1.3403 \\
-2.22\end{array}$ & $\begin{array}{r}-0.7965 \\
-1.31\end{array}$ & $\begin{array}{r}-0.9308 \\
-1.38\end{array}$ & $\begin{array}{r}-1.1804 \\
-1.74\end{array}$ \\
\hline \multicolumn{8}{|c|}{ Testing for the absence of ${ }^{\mathrm{f}}$} \\
\hline - overreaction & 0.0000 & 0.0477 & 0.0967 & 0.0008 & 0.0093 & 0.0269 & 0.0198 \\
\hline $\begin{array}{l}\text { - overshot revision } \\
\text { Long-run interval: }\end{array}$ & 0.0117 & 0.3973 & 0.5537 & 0.0312 & 0.1641 & 0.1337 & 0.1012 \\
\hline - upper-bound & 5.64 & 5.3 & 6. & 6. & & 6.44 & 6.19 \\
\hline - lower-bound & 4.15 & 3.89 & 4.54 & 4.54 & 5.08 & 4.95 & 4.70 \\
\hline
\end{tabular}

( $\left.{ }^{\mathrm{a}}\right)$ The group definition of panel \# 1 is in Table 4.

(b) Maximum likelihood estimates (below, Student-t statistics) of the unrestricted model:

$\Delta E_{t}^{h}\left(\pi_{t+1}\right)=\lambda_{11}^{h} \Delta E_{t}^{F}\left(\pi_{t+1}\right)+\lambda_{12}^{h} \Delta \pi_{t}^{P, h}+\lambda_{13}^{h} \Delta \pi_{t-1}+\lambda_{2}^{h}\left[E_{t-1}^{h}\left(\pi_{t}\right)-\phi_{1}^{h} E_{t-1}^{F}\left(\pi_{t}\right)-\phi_{2}^{h} \pi_{t-1}^{P, h}-\phi_{3}^{h} \pi_{t-2}-\phi_{4}^{h} \pi^{T}\right]+\varepsilon_{t}^{h}$

Then, $\mathrm{p}$-values are reported for each restriction and the following estimates embody such restrictions.

( ${ }^{c}$ ) For each restriction, p-values are reported from models measuring actual inflation with CPI and HICP.

(d) Obtained as a ratio of PMG parameters' estimates: $-\lambda_{10}^{h} / \lambda_{2}^{h}$.

(e) Andrews (1993) and Chow (1960, with exogenous date in 2007m8) tests for parameters break (p-val).

( ${ }^{\mathrm{f}} P$-values of $\mathrm{H}_{\mathrm{o}}: \lambda_{11}^{h}=-\lambda_{2}^{h}$, and $\mathrm{H}_{\mathrm{o}}: \lambda_{11}^{h} /-\lambda_{2}^{h}=\phi_{1}$ respectively; see also Appendix A1.2.

$\left.{ }^{\mathrm{g}}\right)$ Interval estimation of inflation expectations (steady state of the model with unconstrained intercepts). 
Tab 6 - Main estimation results, pseudo panel \# $2^{\text {a }}$

\begin{tabular}{|c|c|c|c|c|c|c|c|c|}
\hline groups: ${ }^{\text {a }}$ & 1 & 2 & 3 & 4 & 5 & 6 & 7 & 8 \\
\hline \multicolumn{9}{|l|}{ Unrestricted model $^{\mathrm{b}}$} \\
\hline$\lambda_{2}^{h}$ & -0.7533 & -0.7591 & -0.4926 & -0.5245 & -0.4851 & -0.4358 & -0.5075 & -0.3761 \\
\hline$t$ & -7.87 & -7.27 & -5.85 & -5.48 & -5.43 & -4.98 & -5.35 & -4.54 \\
\hline & 0.1425 & 0.2272 & 0.0241 & 0.2384 & 0.8901 & 0.5852 & 0.4740 & 0.7084 \\
\hline$\phi_{2}^{h}=\phi_{3}^{h}=0$ & 0.3465 & 0.5431 & 0.2192 & 0.3519 & 0.5349 & 0.2466 & 0.5391 & 0.9058 \\
\hline$\lambda_{13}^{h}=0^{c}$ & 0.5418 & 0.8690 & 0.2155 & 0.1827 & 0.7592 & 0.4115 & 0.7499 & 0.2403 \\
\hline & 0.8948 & 0.6736 & 0.1849 & 0.3795 & 0.4337 & 0.3472 & 0.8483 & 0.0236 \\
\hline$\lambda_{13}^{h}=\phi_{2}^{h}=\phi_{3}^{h}=0^{c}$ & 0.0165 & 0.3014 & 0.0547 & 0.3484 & 0.8452 & 0.7648 & 0.6818 & 0.4173 \\
\hline & 0.4398 & 0.6872 & 0.2861 & 0.5095 & 0.7069 & 0.4051 & 0.7325 & 0.0588 \\
\hline \multicolumn{9}{|l|}{ Restricted model } \\
\hline$\lambda_{11}^{h}$ & 6.9589 & 3.7728 & 2.6051 & 3.8674 & 4.8003 & 2.7543 & 3.8535 & 3.9206 \\
\hline$t$ & 4.21 & 1.80 & 2.00 & 2.64 & 3.12 & 1.81 & 2.16 & 2.31 \\
\hline$\lambda_{12}^{h}$ & 0.1793 & 0.1771 & 0.3024 & 0.1530 & 0.2183 & 0.1526 & 0.0691 & 0.1137 \\
\hline$t$ & 3.61 & 3.84 & 5.80 & 3.68 & 3.73 & 3.46 & 1.86 & 2.89 \\
\hline$\lambda_{2}^{h}$ & -0.7471 & -0.7405 & -0.4236 & -0.5012 & -0.4805 & -0.4339 & -0.4813 & -0.3657 \\
\hline$t$ & -7.62 & -7.15 & -5.22 & -5.32 & -5.50 & -5.06 & -5.30 & -4.58 \\
\hline$\phi_{1}^{h}$ & 2.5977 & 3.2896 & 3.5015 & 3.7303 & 4.3175 & 4.3298 & 4.2481 & 4.0537 \\
\hline$t$ & 5.02 & 4.77 & 4.75 & 5.44 & 5.50 & 5.04 & 4.57 & 3.54 \\
\hline$\phi_{4}^{h} \pi^{T} \mathrm{~d}$ & -0.6983 & -0.9222 & -1.9467 & -1.2916 & -2.7729 & -2.4102 & -2.6362 & -2.4800 \\
\hline$t$ & -0.68 & -0.67 & -1.33 & -0.95 & -1.77 & -1.41 & -1.43 & -1.09 \\
\hline $\mathrm{R}^{2}$ & 0.4866 & 0.4830 & 0.4513 & 0.3597 & 0.4188 & 0.3519 & 0.2850 & 0.3096 \\
\hline Andrews break ${ }^{\mathrm{e}}$ & 0.0553 & 0.1114 & 0.4244 & 0.0896 & 0.0437 & 0.1442 & 0.0633 & 0.6144 \\
\hline Chow break ${ }^{\mathrm{e}}$ & 0.0438 & 0.4191 & 0.3912 & 0.2986 & 0.1569 & 0.5261 & 0.1656 & 0.0943 \\
\hline$\phi_{1}^{h}=\phi_{1}$ & 0.5033 & & & & & & & \\
\hline \multicolumn{9}{|l|}{ PMG model } \\
\hline$\lambda_{11}^{h}$ & 7.1565 & 3.8481 & 2.6079 & 3.7850 & 4.5828 & 2.5509 & 3.6698 & 3.8269 \\
\hline$t$ & 4.38 & 1.89 & 2.08 & 2.70 & 3.08 & 1.73 & 2.12 & 2.33 \\
\hline$\lambda_{12}^{h}$ & 0.1784 & 0.1768 & 0.3024 & 0.1535 & 0.2221 & 0.1554 & 0.0704 & 0.1147 \\
\hline$t$ & 3.63 & 3.94 & 5.97 & 3.80 & 3.88 & 3.62 & 1.94 & 3.00 \\
\hline$\lambda_{2}^{h}$ & -0.7322 & -0.7414 & -0.4238 & -0.4949 & -0.4564 & -0.4131 & -0.4672 & -0.3603 \\
\hline$t$ & -7.57 & -7.36 & -5.44 & -5.51 & -5.54 & -5.10 & -5.37 & -4.68 \\
\hline$\phi_{1}$ & 3.5115 & 3.5115 & 3.5115 & 3.5115 & 3.5115 & 3.5115 & 3.5115 & 3.5115 \\
\hline$t$ & 13.39 & 13.39 & 13.39 & 13.39 & 13.39 & 13.39 & 13.39 & 13.39 \\
\hline$\phi_{4}^{h} \pi^{T}$ d & -2.4824 & -1.3557 & -1.9662 & -0.8633 & -1.1920 & -0.8091 & -1.1972 & -1.4195 \\
\hline$t$ & -4.55 & -2.39 & -3.42 & -1.52 & -2.01 & -1.34 & -1.95 & -2.16 \\
\hline \multicolumn{9}{|c|}{ Testing for the absence of ${ }^{\mathrm{f}}$} \\
\hline - overreaction & 0.0000 & 0.0493 & 0.0297 & 0.0044 & 0.0051 & 0.0908 & 0.0408 & 0.0365 \\
\hline - overshot revision & 0.0027 & 0.5251 & 0.3509 & 0.1246 & 0.0694 & 0.4664 & 0.2588 & 0.1619 \\
\hline \multicolumn{9}{|l|}{ Long-run interval: ${ }^{\mathrm{g}}$} \\
\hline - upper-bound & 5.03 & 6.16 & 5.55 & 6.65 & 6.32 & 6.71 & 6.32 & 6.10 \\
\hline - lower-bound & 3.51 & 4.64 & 4.03 & 5.13 & 4.81 & 5.19 & 4.80 & 4.58 \\
\hline
\end{tabular}

${ }^{\mathrm{a}}$ ) The group definition of panel \# 2 is in Table 4.

$\left({ }^{b}\right)$ Maximum likelihood estimates (below, Student-t statistics) of the unrestricted model: $\Delta E_{t}^{h}\left(\pi_{t+1}\right)=\lambda_{11}^{h} \Delta E_{t}^{F}\left(\pi_{t+1}\right)+\lambda_{12}^{h} \Delta \pi_{t}^{P, h}+\lambda_{13}^{h} \Delta \pi_{t-1}+\lambda_{2}^{h}\left[E_{t-1}^{h}\left(\pi_{t}\right)-\phi_{1}^{h} E_{t-1}^{F}\left(\pi_{t}\right)-\phi_{2}^{h} \pi_{t-1}^{P, h}-\phi_{3}^{h} \pi_{t-2}-\phi_{4}^{h} \pi^{T}\right]+\varepsilon_{t}^{h}$

Then, p-values are reported for each restriction and the following estimates embody such restrictions.

${ }^{c}$ ) For each restriction, p-values are reported from models measuring actual inflation with CPI and HICP.

(') Obtained as a ratio of PMG parameters' estimates: $-\lambda_{10}^{h} / \lambda_{2}^{h}$.

$\left(^{e}\right)$ Andrews (1993) and Chow (1960, with exogenous date in 2007m8) tests for parameters break (p-val).

$\left.{ }_{(}^{f}\right) P$-values of $\mathrm{H}_{0}: \lambda_{11}^{h}=-\lambda_{2}^{h}$, and $\mathrm{H}_{0}: \lambda_{11}^{h} /-\lambda_{2}^{h}=\phi_{1}$ respectively; see also Appendix A1.2.

${ }^{(g)}$ Interval estimation of inflation expectations (steady state of the model with unconstrained intercepts). 
Tab 8 - Main estimation results, pseudo panel \# $4^{\mathrm{a}}$

\begin{tabular}{|c|c|c|c|c|c|c|c|c|}
\hline groups: ${ }^{\text {a }}$ & 1 & 2 & 3 & 4 & 5 & 6 & 7 & 8 \\
\hline \multicolumn{9}{|l|}{ Unrestricted model $^{\mathrm{b}}$} \\
\hline $\begin{array}{r}\lambda_{2}^{h} \\
t\end{array}$ & $\begin{array}{r}-0.7019 \\
-7.44\end{array}$ & $\begin{array}{r}-0.5715 \\
-6.27\end{array}$ & $\begin{array}{r}-0.4854 \\
-5.41\end{array}$ & $\begin{array}{r}-0.4648 \\
-5.08\end{array}$ & $\begin{array}{r}-0.8058 \\
-7.8\end{array}$ & $\begin{array}{r}-0.6283 \\
-6.3\end{array}$ & $\begin{array}{r}-0.4469 \\
-5.21\end{array}$ & $\begin{array}{r}-0.2541 \\
-3.59\end{array}$ \\
\hline$\phi_{2}^{h}=\phi_{3}^{h}=0^{c}$ & $\begin{array}{l}0.1898 \\
0.3241\end{array}$ & $\begin{array}{l}0.0841 \\
0.7123\end{array}$ & $\begin{array}{l}0.1392 \\
0.2426\end{array}$ & $\begin{array}{l}0.6558 \\
0.5512\end{array}$ & $\begin{array}{l}0.5487 \\
0.2185\end{array}$ & $\begin{array}{l}0.7005 \\
0.7152\end{array}$ & $\begin{array}{l}0.4353 \\
0.5053\end{array}$ & $\begin{array}{l}0.6650 \\
0.8478\end{array}$ \\
\hline$\lambda_{13}^{h}=0^{c}$ & $\begin{array}{l}0.5627 \\
0.5185\end{array}$ & $\begin{array}{l}0.4181 \\
0.9254\end{array}$ & $\begin{array}{l}0.7619 \\
0.2359\end{array}$ & $\begin{array}{l}0.8649 \\
0.5502\end{array}$ & $\begin{array}{l}0.9308 \\
0.2564\end{array}$ & $\begin{array}{l}0.2597 \\
0.6769\end{array}$ & $\begin{array}{l}0.5410 \\
0.6107\end{array}$ & $\begin{array}{l}0.3197 \\
0.1802\end{array}$ \\
\hline$\lambda_{13}^{h}=\phi_{2}^{h}=\phi_{3}^{h}=0^{c}$ & $\begin{array}{l}0.0601 \\
0.5154\end{array}$ & $\begin{array}{l}0.1370 \\
0.8451\end{array}$ & $\begin{array}{l}0.0802 \\
0.3363\end{array}$ & $\begin{array}{l}0.8373 \\
0.7285\end{array}$ & $\begin{array}{l}0.5987 \\
0.2446\end{array}$ & $\begin{array}{l}0.7267 \\
0.8761\end{array}$ & $\begin{array}{l}0.6422 \\
0.4905\end{array}$ & $\begin{array}{l}0.3230 \\
0.3991\end{array}$ \\
\hline \multicolumn{9}{|l|}{ Restricted model } \\
\hline $\begin{array}{c}\lambda_{11}^{h} \\
t\end{array}$ & $\begin{array}{r}9.6576 \\
4.36\end{array}$ & $\begin{array}{r}4.0616 \\
2.78\end{array}$ & $\begin{array}{r}1.7330 \\
1.14\end{array}$ & $\begin{array}{r}5.4828 \\
3.86\end{array}$ & $\begin{array}{r}4.2562 \\
1.44\end{array}$ & $\begin{array}{r}5.5953 \\
3.67\end{array}$ & $\begin{array}{r}3.0420 \\
2.07\end{array}$ & $\begin{array}{r}0.9736 \\
0.73\end{array}$ \\
\hline $\begin{array}{c}\lambda_{12}^{h} \\
t\end{array}$ & $\begin{array}{r}0.1925 \\
3.66\end{array}$ & $\begin{array}{r}0.3069 \\
5.64\end{array}$ & $\begin{array}{r}0.2305 \\
4.36\end{array}$ & $\begin{array}{r}0.0520 \\
1.01\end{array}$ & $\begin{array}{r}0.1944 \\
3.43\end{array}$ & $\begin{array}{r}0.1110 \\
2.75\end{array}$ & $\begin{array}{r}0.1792 \\
4.05\end{array}$ & $\begin{array}{r}0.1545 \\
4.37\end{array}$ \\
\hline $\begin{array}{r}\lambda_{2}^{h} \\
t\end{array}$ & $\begin{array}{r}-0.6785 \\
-7.07\end{array}$ & $\begin{array}{r}-0.5257 \\
-5.88\end{array}$ & $\begin{array}{r}-0.4467 \\
-5.16\end{array}$ & $\begin{array}{r}-0.4494 \\
-5.07\end{array}$ & $\begin{array}{r}-0.8041 \\
-7.84\end{array}$ & $\begin{array}{r}-0.6343 \\
-6.48\end{array}$ & $\begin{array}{r}-0.4230 \\
-5.15\end{array}$ & $\begin{array}{r}-0.2473 \\
-3.63\end{array}$ \\
\hline $\begin{array}{r}\phi_{1}^{h} \\
t\end{array}$ & $\begin{array}{r}3.9914 \\
5.13\end{array}$ & $\begin{array}{r}3.7621 \\
5.92\end{array}$ & $\begin{array}{r}3.3530 \\
4.02\end{array}$ & $\begin{array}{r}4.0175 \\
5.09\end{array}$ & $\begin{array}{r}4.2977 \\
4.66\end{array}$ & $\begin{array}{r}3.9555 \\
6.87\end{array}$ & $\begin{array}{r}3.7557 \\
4.43\end{array}$ & $\begin{array}{r}3.5834 \\
2.65\end{array}$ \\
\hline $\begin{array}{c}\phi_{4}^{h} \pi^{T} \mathrm{~d} \\
t\end{array}$ & $\begin{array}{r}-2.2440 \\
-1.45\end{array}$ & $\begin{array}{r}-1.9383 \\
-1.53\end{array}$ & $\begin{array}{r}-1.4134 \\
-0.85\end{array}$ & $\begin{array}{r}-3.0355 \\
-1.93\end{array}$ & $\begin{array}{r}-1.3425 \\
-0.73\end{array}$ & $\begin{array}{r}-1.3329 \\
-1.16\end{array}$ & $\begin{array}{r}-1.5389 \\
-0.91\end{array}$ & $\begin{array}{r}-2.1898 \\
-0.82\end{array}$ \\
\hline $\mathrm{R}^{2}$ & 0.4837 & 0.4915 & 0.3754 & 0.3434 & 0.5128 & 0.4037 & 0.3518 & 0.3029 \\
\hline $\begin{array}{l}\text { Andrews break } \\
\text { Chow break }\end{array}$ & $\begin{array}{l}0.1356 \\
0.0581\end{array}$ & $\begin{array}{l}0.0385 \\
0.0584\end{array}$ & $\begin{array}{l}0.4532 \\
0.6905\end{array}$ & $\begin{array}{l}0.1230 \\
0.1994\end{array}$ & $\begin{array}{l}0.0716 \\
0.0414\end{array}$ & $\begin{array}{l}0.0638 \\
0.1355\end{array}$ & $\begin{array}{l}0.6840 \\
0.5717\end{array}$ & $\begin{array}{l}0.2634 \\
0.3925\end{array}$ \\
\hline$\phi_{1}^{h}=\phi_{1}$ & 0.9972 & & & & & & & \\
\hline \multicolumn{9}{|l|}{$P M G$ model } \\
\hline $\begin{array}{c}\lambda_{11}^{h} \\
t\end{array}$ & $\begin{array}{r}9.5964 \\
4.50\end{array}$ & $\begin{array}{r}4.0938 \\
2.90\end{array}$ & $\begin{array}{r}1.8423 \\
1.26\end{array}$ & $\begin{array}{r}5.4506 \\
3.97\end{array}$ & $\begin{array}{r}4.0996 \\
1.44\end{array}$ & $\begin{array}{r}5.5553 \\
3.78\end{array}$ & $\begin{array}{r}3.0649 \\
2.16\end{array}$ & $\begin{array}{r}1.0042 \\
0.78\end{array}$ \\
\hline $\begin{array}{c}\lambda_{12}^{h} \\
t\end{array}$ & $\begin{array}{r}0.1927 \\
3.77\end{array}$ & $\begin{array}{r}0.3069 \\
5.80\end{array}$ & $\begin{array}{r}0.2287 \\
4.44\end{array}$ & $\begin{array}{r}0.0526 \\
1.05\end{array}$ & $\begin{array}{r}0.1949 \\
3.54\end{array}$ & $\begin{array}{r}0.1113 \\
2.83\end{array}$ & $\begin{array}{r}0.1790 \\
4.17\end{array}$ & $\begin{array}{r}0.1541 \\
4.49\end{array}$ \\
\hline $\begin{array}{r}\lambda_{2}^{h} \\
t\end{array}$ & $\begin{array}{r}-0.6755 \\
-7.34\end{array}$ & $\begin{array}{r}-0.5274 \\
-6.11\end{array}$ & $\begin{array}{r}-0.4485 \\
-5.32\end{array}$ & $\begin{array}{r}-0.4482 \\
-5.21\end{array}$ & $\begin{array}{r}-0.8012 \\
-8.04\end{array}$ & $\begin{array}{r}-0.6315 \\
-6.71\end{array}$ & $\begin{array}{r}-0.4240 \\
-5.33\end{array}$ & $\begin{array}{r}-0.2476 \\
-3.74\end{array}$ \\
\hline $\begin{array}{c}\phi_{1} \\
t\end{array}$ & $\begin{array}{r}3.8579 \\
14.46\end{array}$ & $\begin{array}{r}3.8579 \\
14.46\end{array}$ & $\begin{array}{r}3.8579 \\
14.46\end{array}$ & $\begin{array}{r}3.8579 \\
14.46\end{array}$ & $\begin{array}{r}3.8579 \\
14.46\end{array}$ & $\begin{array}{r}3.8579 \\
14.46\end{array}$ & $\begin{array}{r}3.8579 \\
14.46\end{array}$ & $\begin{array}{r}3.8579 \\
14.46\end{array}$ \\
\hline $\begin{array}{c}\phi_{4}^{h} \pi^{T} \quad \mathrm{~d} \\
t\end{array}$ & $\begin{array}{r}-1.9827 \\
-3.36\end{array}$ & $\begin{array}{r}-2.1258 \\
-3.74\end{array}$ & $\begin{array}{r}-2.4003 \\
-4.01\end{array}$ & $\begin{array}{r}-2.7233 \\
-4.59\end{array}$ & $\begin{array}{r}-0.4829 \\
-0.78\end{array}$ & $\begin{array}{r}-1.1419 \\
-2.04\end{array}$ & $\begin{array}{r}-1.7389 \\
-2.89\end{array}$ & $\begin{array}{r}-2.7265 \\
-3.85\end{array}$ \\
\hline $\begin{array}{l}\text { Testing for the absenc } \\
\text { - overreaction } \\
\text { - overshot revision }\end{array}$ & $\begin{array}{l}\text { of }{ }^{\mathrm{f}} \\
0.0000 \\
0.0009\end{array}$ & $\begin{array}{l}0.0016 \\
0.1138\end{array}$ & $\begin{array}{l}0.1949 \\
0.9371\end{array}$ & $\begin{array}{l}0.0020 \\
0.0354\end{array}$ & $\begin{array}{l}0.1538 \\
0.7258\end{array}$ & $\begin{array}{l}0.0002 \\
0.0342\end{array}$ & $\begin{array}{l}0.0314 \\
0.3160\end{array}$ & $\begin{array}{l}0.4348 \\
0.9695\end{array}$ \\
\hline $\begin{array}{l}\text { Long-run interval: }{ }^{\mathrm{g}} \\
\text { - upper-bound } \\
\text { - lower-bound }\end{array}$ & $\begin{array}{l}6.27 \\
4.61 \\
\end{array}$ & $\begin{array}{l}6.13 \\
4.46 \\
\end{array}$ & $\begin{array}{l}5.86 \\
4.19 \\
\end{array}$ & $\begin{array}{l}5.53 \\
3.87 \\
\end{array}$ & $\begin{array}{l}7.77 \\
6.11 \\
\end{array}$ & $\begin{array}{l}7.11 \\
5.45 \\
\end{array}$ & $\begin{array}{l}6.52 \\
4.85 \\
\end{array}$ & $\begin{array}{l}5.53 \\
3.86 \\
\end{array}$ \\
\hline
\end{tabular}

$\left({ }^{\mathrm{a}}\right)$ The group definition of panel \# 4 is in Table 4.

( ) Maximum likelihood estimates (below, Student-t statistics) of the unrestricted model:

$\Delta E_{t}^{h}\left(\pi_{t+1}\right)=\lambda_{11}^{h} \Delta E_{t}^{F}\left(\pi_{t+1}\right)+\lambda_{12}^{h} \Delta \pi_{t}^{P, h}+\lambda_{13}^{h} \Delta \pi_{t-1}+\lambda_{2}^{h}\left[E_{t-1}^{h}\left(\pi_{t}\right)-\phi_{1}^{h} E_{t-1}^{F}\left(\pi_{t}\right)-\phi_{2}^{h} \pi_{t-1}^{P, h}-\phi_{3}^{h} \pi_{t-2}-\phi_{4}^{h} \pi^{T}\right]+\varepsilon_{t}^{h}$

Then, p-values are reported for each restriction and the following estimates embody such restrictions.

$\left.{ }^{(}{ }^{c}\right)$ For each restriction, p-values are reported from models measuring actual inflation with CPI and HICP.

${ }^{(d)}$ Obtained as a ratio of PMG parameters' estimates: $-\lambda_{10}^{h} / \lambda_{2}^{h}$.

$\left({ }^{e}\right)$ Andrews (1993) and Chow (1960, with exogenous date in 2007m8) tests for parameters break (p-val).

() $P$-values of $\mathrm{H}_{0}: \lambda_{11}^{h}=-\lambda_{2}^{h}$, and $\mathrm{H}_{0}: \lambda_{11}^{h} /-\lambda_{2}^{h}=\phi_{1}$ respectively; see also Appendix A1.2.

$\left({ }^{g}\right)$ Interval estimation of inflation expectations (steady state of the model with unconstrained intercepts). 
Tab 7

Main estimation results, pseudo panel \# $3^{\text {a }}$

\begin{tabular}{|c|c|c|c|c|c|c|c|c|c|c|}
\hline groups: $^{a}$ & 1 & 2 & 3 & 4 & 5 & 6 & 7 & 8 & 9 & 10 \\
\hline \multicolumn{11}{|l|}{ Unrestricted model (8) } \\
\hline $\begin{array}{r}\lambda_{2}^{h} \\
t\end{array}$ & $\begin{array}{r}-0.6252 \\
-5.93\end{array}$ & $\begin{array}{r}-0.8424 \\
-8.01\end{array}$ & $\begin{array}{r}-0.5084 \\
-5.67\end{array}$ & $\begin{array}{r}-0.5791 \\
-6.02\end{array}$ & $\begin{array}{r}-0.4438 \\
-5.02\end{array}$ & $\begin{array}{r}-0.8458 \\
-7.54\end{array}$ & $\begin{array}{r}-0.4375 \\
-5.07\end{array}$ & $\begin{array}{r}-0.3180 \\
-4.05\end{array}$ & $\begin{array}{r}-0.8072 \\
-8.44\end{array}$ & $\begin{array}{r}-0.4557 \\
-5.11\end{array}$ \\
\hline$\phi_{2}^{h}=\phi_{3}^{h}=0^{c}$ & $\begin{array}{l}0.1299 \\
0.6130\end{array}$ & $\begin{array}{l}0.3836 \\
0.4222\end{array}$ & $\begin{array}{l}0.1287 \\
0.1017\end{array}$ & $\begin{array}{l}0.2333 \\
0.7756\end{array}$ & $\begin{array}{l}0.4110 \\
0.6277\end{array}$ & $\begin{array}{l}0.6478 \\
0.0925\end{array}$ & $\begin{array}{l}0.4878 \\
0.4682\end{array}$ & $\begin{array}{l}0.7079 \\
0.8182\end{array}$ & $\begin{array}{l}0.1552 \\
0.2989\end{array}$ & $\begin{array}{l}0.5689 \\
0.2818\end{array}$ \\
\hline$\lambda_{13}^{h}=0^{c}$ & $\begin{array}{l}0.3720 \\
0.9801\end{array}$ & $\begin{array}{l}0.2107 \\
0.2822\end{array}$ & $\begin{array}{l}0.8001 \\
0.1578\end{array}$ & $\begin{array}{l}0.4338 \\
0.8887\end{array}$ & $\begin{array}{l}0.1880 \\
0.4168\end{array}$ & $\begin{array}{l}0.9205 \\
0.6520\end{array}$ & $\begin{array}{l}0.6479 \\
0.9802\end{array}$ & $\begin{array}{l}0.6981 \\
0.1965\end{array}$ & $\begin{array}{l}0.9975 \\
0.2497\end{array}$ & $\begin{array}{l}0.3338 \\
0.7468\end{array}$ \\
\hline$\lambda_{13}^{h}=\phi_{2}^{h}=\phi_{3}^{h}=0^{c}$ & $\begin{array}{l}0.0139 \\
0.7980\end{array}$ & $\begin{array}{l}0.1640 \\
0.4228\end{array}$ & $\begin{array}{l}0.1673 \\
0.1719\end{array}$ & $\begin{array}{l}0.3910 \\
0.8913\end{array}$ & $\begin{array}{l}0.4824 \\
0.7056\end{array}$ & $\begin{array}{l}0.8130 \\
0.1771\end{array}$ & $\begin{array}{l}0.4903 \\
0.6478\end{array}$ & $\begin{array}{l}0.7839 \\
0.4956\end{array}$ & $\begin{array}{l}0.1907 \\
0.3477\end{array}$ & $\begin{array}{l}0.7025 \\
0.4514\end{array}$ \\
\hline \multicolumn{11}{|l|}{ Restricted model } \\
\hline $\begin{array}{c}\lambda_{11}^{h} \\
t\end{array}$ & $\begin{array}{r}3.5152 \\
1.96\end{array}$ & $\begin{array}{r}1.9072 \\
1.02\end{array}$ & $\begin{array}{r}3.6668 \\
2.36\end{array}$ & $\begin{array}{r}4.9156 \\
2.85\end{array}$ & $\begin{array}{r}2.0794 \\
1.16\end{array}$ & $\begin{array}{r}3.4645 \\
1.24\end{array}$ & $\begin{array}{r}4.4004 \\
3.31\end{array}$ & $\begin{array}{r}1.7649 \\
1.18\end{array}$ & $\begin{array}{r}8.2800 \\
3.84\end{array}$ & $\begin{array}{r}3.6693 \\
2.58\end{array}$ \\
\hline $\begin{array}{c}\lambda_{12}^{h} \\
t\end{array}$ & $\begin{array}{r}0.1102 \\
2.53\end{array}$ & $\begin{array}{r}0.1012 \\
2.79\end{array}$ & $\begin{array}{r}0.2755 \\
5.25\end{array}$ & $\begin{array}{r}0.1630 \\
3.71\end{array}$ & $\begin{array}{r}0.2712 \\
6.06\end{array}$ & $\begin{array}{r}0.0410 \\
0.92\end{array}$ & $\begin{array}{r}0.1745 \\
3.09\end{array}$ & $\begin{array}{r}0.1289 \\
3.36\end{array}$ & $\begin{array}{r}0.2171 \\
4.37\end{array}$ & $\begin{array}{r}0.1204 \\
2.95\end{array}$ \\
\hline $\begin{array}{r}\lambda_{2}^{h} \\
t\end{array}$ & $\begin{array}{r}-0.6483 \\
-5.98\end{array}$ & $\begin{array}{r}-0.8203 \\
-8.03\end{array}$ & $\begin{array}{r}-0.4597 \\
-5.30\end{array}$ & $\begin{array}{r}-0.5572 \\
-5.85\end{array}$ & $\begin{array}{r}-0.4059 \\
-4.81\end{array}$ & $\begin{array}{r}-0.8393 \\
-7.62\end{array}$ & $\begin{array}{r}-0.4115 \\
-4.93\end{array}$ & $\begin{array}{r}-0.3025 \\
-4.06\end{array}$ & $\begin{array}{r}-0.7609 \\
-8.09\end{array}$ & $\begin{array}{r}-0.4488 \\
-5.16\end{array}$ \\
\hline $\begin{array}{c}\phi_{1}^{h} \\
t\end{array}$ & $\begin{array}{r}3.2811 \\
5.06\end{array}$ & $\begin{array}{r}3.4540 \\
6.08\end{array}$ & $\begin{array}{r}3.3516 \\
4.13\end{array}$ & $\begin{array}{r}3.8365 \\
5.23\end{array}$ & $\begin{array}{r}3.5800 \\
3.48\end{array}$ & $\begin{array}{r}4.5663 \\
5.55\end{array}$ & $\begin{array}{r}4.1192 \\
5.11\end{array}$ & $\begin{array}{r}3.0592 \\
2.48\end{array}$ & $\begin{array}{r}3.1947 \\
4.61\end{array}$ & $\begin{array}{r}4.3332 \\
5.53\end{array}$ \\
\hline $\begin{array}{c}\phi_{4}^{h} \pi^{T} \mathrm{~d} \\
t\end{array}$ & $\begin{array}{r}-2.0887 \\
-1.62\end{array}$ & $\begin{array}{r}-2.0869 \\
-1.85\end{array}$ & $\begin{array}{r}-1.4463 \\
-0.90\end{array}$ & $\begin{array}{r}-1.4173 \\
-0.97\end{array}$ & $\begin{array}{r}-0.7127 \\
-0.35\end{array}$ & $\begin{array}{r}-2.3523 \\
-1.44\end{array}$ & $\begin{array}{r}-2.9962 \\
-1.87\end{array}$ & $\begin{array}{r}-0.9352 \\
-0.38\end{array}$ & $\begin{array}{r}-0.5429 \\
-0.39\end{array}$ & $\begin{array}{r}-2.3871 \\
-1.53\end{array}$ \\
\hline $\mathrm{R}^{2}$ & 0.3565 & 0.4757 & 0.4601 & 0.3958 & 0.4623 & 0.4122 & 0.3686 & 0.2591 & 0.5705 & 0.3369 \\
\hline $\begin{array}{l}\text { Andrews break }{ }^{\mathrm{e}} \\
\text { Chow break }{ }^{\mathrm{e}}\end{array}$ & $\begin{array}{l}0.1649 \\
0.0742\end{array}$ & $\begin{array}{l}0.3638 \\
0.1359\end{array}$ & $\begin{array}{l}0.0464 \\
0.4599\end{array}$ & $\begin{array}{l}0.0941 \\
0.1069\end{array}$ & $\begin{array}{l}0.2484 \\
0.2446\end{array}$ & $\begin{array}{l}0.2293 \\
0.1777\end{array}$ & $\begin{array}{l}0.1043 \\
0.0803\end{array}$ & $\begin{array}{l}0.4161 \\
0.2120\end{array}$ & $\begin{array}{l}0.1357 \\
0.0782\end{array}$ & $\begin{array}{l}0.1301 \\
0.3027\end{array}$ \\
\hline$\phi_{1}^{h}=\phi_{1}$ & 0.9269 & & & & & & & & & \\
\hline
\end{tabular}




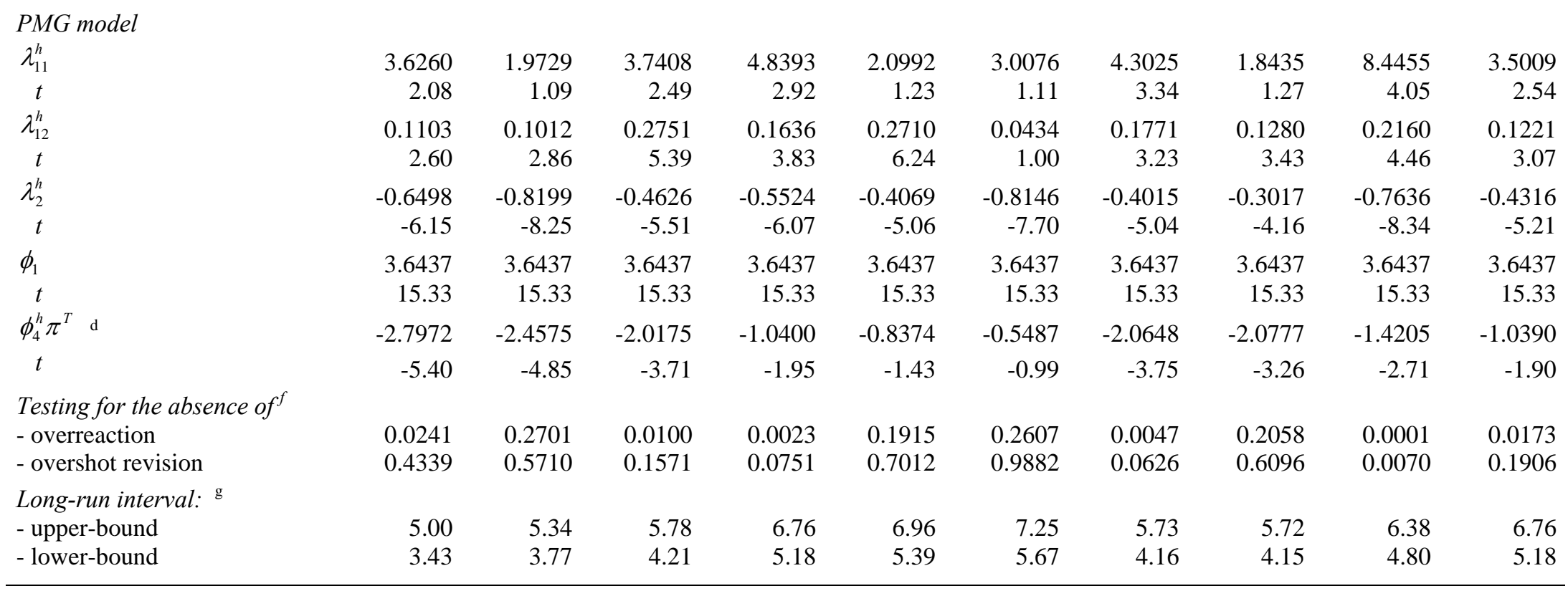

(a) The group definition of panel \# 3 is in Table 4.

(b) Maximum likelihood estimates (below, Student-t statistics) of the unrestricted model:

$\Delta E_{t}^{h}\left(\pi_{t+1}\right)=\lambda_{11}^{h} \Delta E_{t}^{F}\left(\pi_{t+1}\right)+\lambda_{12}^{h} \Delta \pi_{t}^{P, h}+\lambda_{13}^{h} \Delta \pi_{t-1}+\lambda_{2}^{h}\left[E_{t-1}^{h}\left(\pi_{t}\right)-\phi_{1}^{h} E_{t-1}^{F}\left(\pi_{t}\right)-\phi_{2}^{h} \pi_{t-1}^{P, h}-\phi_{3}^{h} \pi_{t-2}-\phi_{4}^{h} \pi^{T}\right]+\varepsilon_{t}^{h}$ Then, p-values are reported for each restriction and the following estimates embody such restrictions.

(c) For each restriction, p-values are reported from models measuring actual inflation with CPI and HICP.

$\left({ }^{\mathrm{d}}\right)$ Obtained as a ratio of PMG parameters' estimates: $-\lambda_{10}^{h} / \lambda_{2}^{h}$.

(') Andrews (1993) and Chow (1960, with exogenous date in 2007m8) tests for parameters break (p-val).

$\left.{ }^{(}{ }^{\mathrm{f}}\right) P$-values of $\mathrm{H}_{0}: \lambda_{11}^{h}=-\lambda_{2}^{h}$, and $\mathrm{H}_{0}: \lambda_{11}^{h} /-\lambda_{2}^{h}=\phi_{1}$ respectively; see also Appendix A1.2.

$\left({ }^{g}\right)$ Interval estimation of inflation expectations (steady state of the model with unconstrained intercepts). 
Tab 9 - Nonlinear modeling: main estimation results with all pseudo panels ${ }^{\text {a }}$

estimates ${ }^{\mathrm{b}}$ and tests ${ }^{\mathrm{c}}$ :

panel \# 1

Extending PMG to linear gap effects ${ }^{\mathrm{d}}$

- long-run pooled gap effect $=0$

- long- and short-run gap effects $=0$

Nonlinear gap effects PMG model ${ }^{\mathrm{e}}$

0.1659

- long-run asymmetry: $\phi_{5}+\phi_{6}=0$

0.3815

0.3052

0.2065

0.3680

0.3519

0.2300

0.0973

- short-run gap effect: $\lambda_{14}^{h}=0$

0.7883

- nonlinear dynamics: $\lambda_{2 N}^{h}=\lambda_{2 N}$

0.4021

- joint LR test of the restrictions above

0.8360

Restricted nonlinear PMG model ${ }^{\mathrm{f}}$

$\lambda_{2 P}^{h}$

$\lambda_{2 P}^{h}+\lambda_{2 N}$

$\phi_{1 P}=\phi_{1}+\phi_{5} \mathrm{~g}$

inflation effect when gap $>0=-\phi_{5}$ h

$\phi_{1 N}=\phi_{1}$

Testing for the absence of ${ }^{\mathrm{i}}$

- overreaction with gap $>0$

- overreaction with gap $<0$

- overshot revision with gap $>0$

- overshot revision with gap $<0$

Long-run expected inflation bound: ${ }^{1}$

0.8163

- upper-bound

- lower-bound

$\begin{array}{rrrrrrr}-0.7524 & -0.8852 & -0.5073 & -0.6271 & -0.7913 & -0.4108 & -0.3900 \\ -7.11 & -7.81 & -5.41 & -6.16 & -7.44 & -4.74 & -4.45 \\ -0.5682 & -0.701 & -0.3231 & -0.4429 & -0.6071 & -0.2266 & -0.2058 \\ -5.23 & -6.05 & -3.33 & -4.23 & -5.59 & -2.53 & -2.23 \\ 6.0267 & 6.0267 & 6.0267 & 6.0267 & 6.0267 & 6.0267 & 6.0267 \\ 11.89 & 11.89 & 11.89 & 11.89 & 11.89 & 11.89 & 11.89 \\ -2.7637 & -2.7637 & -2.7637 & -2.7637 & -2.7637 & -2.7637 & -2.7637 \\ -6.3 & -6.3 & -6.3 & -6.3 & -6.3 & -6.3 & -6.3 \\ 3.2629 & 3.2629 & 3.2629 & 3.2629 & 3.2629 & 3.2629 & 3.2629 \\ 12.02 & 12.02 & 12.02 & 12.02 & 12.02 & 12.02 & 12.02 \\ & & & & & & \\ 0.0003 & 0.1246 & 0.0983 & 0.0015 & 0.0147 & 0.0338 & 0.0374 \\ 0.0005 & 0.1207 & 0.1003 & 0.0033 & 0.0154 & 0.0829 & 0.1059 \\ 0.7331 & 0.5198 & 0.3822 & 0.7104 & 0.6916 & 0.649 & 0.5755 \\ 0.0631 & 0.7271 & 0.7856 & 0.0956 & 0.3691 & 0.2209 & 0.2071 \\ 4.65 & 4.41 & 4.98 & 4.96 & 5.45 & 5.34 & 5.11 \\ 3.24 & 3.00 & 3.57 & 3.55 & 4.04 & 3.93 & 3.70\end{array}$




\section{panel \# 2}

Extending PMG to linear gap effects ${ }^{\mathrm{d}}$

- long-run pooled gap effect $=0$

- long- and short-run gap effects $=0$

Nonlinear gap effects PMG model ${ }^{\mathrm{e}}$

- long-run asymmetry: $\phi_{5}+\phi_{6}=0$

0.5239

0.5561

0.2600

0.5574

0.3207

0.4443

0.3628

0.0313

- short-run gap effect: $\lambda_{14}^{h}=0$

0.7083

- nonlinear dynamics: $\lambda_{2 N}^{h}=\lambda_{2 N}$

0.2035

- joint LR test of the restrictions above

0.6717

0.4951

Restricted nonlinear PMG model ${ }^{\mathrm{f}}$

$\lambda_{2 P}^{h}$

$\lambda_{2 P}^{h}+\lambda_{2 N}$

$\phi_{1 P}=\phi_{1}+\phi_{5} \mathrm{~g}$

inflation effect when gap $>0=-\phi_{5}$ h

$$
-7.57
$$

$-0.8655$

0.5451

$-6.04$

$-0.6417$

$-0.6459$

$-0.5322$

$-0.5555$

$-0.4622$

$-0.6721$

$-0.6837 \quad-0.3632$

$-6.75$

$-5.42$

$-5.30$

$-4.94$

$-5.94$

$-6.01-3.92$

$-0.4598$

$-0.3504$

$-0.3737$

$-0.2804$

$6.1151 \quad 6.1151 \quad 6.1151$

6.1151

$-3.47 \quad-2.90$

13.06

13.06

13.06

13.06

6.1151

$6.1151 \quad 6.1151$

$-2.7717$

$-2.7717$

$-2.7717$

$-2.7717$

13.06

13.06

$13.06 \quad 13.06$

$-6.86$

$-6.86-6.86$

$-6.86$

$-2.7717$

$-2.7717$

$-2.7717$

$-2.7717$

3.3434

3.3434

3.3434

3.3434

3.3434

$-6.86$

$-6.86$

$-6.86$

Testing for the absence of ${ }^{\mathrm{i}}$

- overreaction with gap $>0$

- overreaction with gap $<0$

- overshot revision with gap $>0$

- overshot revision with gap $<0$

Long-run expected inflation bound: ${ }^{1}$

- upper-bound

- lower-bound

$\begin{array}{rrrrrrrr}0.0000 & 0.1329 & 0.0423 & 0.0060 & 0.0050 & 0.1578 & 0.0781 & 0.0640 \\ 0.0000 & 0.1305 & 0.0466 & 0.0075 & 0.0084 & 0.1717 & 0.0956 & 0.1010 \\ 0.3851 & 0.2387 & 0.4396 & 0.7955 & 0.8411 & 0.4585 & 0.9160 & 0.7795 \\ 0.0145 & 0.9855 & 0.6265 & 0.2700 & 0.1660 & 0.8198 & 0.4593 & 0.3199 \\ & & & & & & & \\ 4.12 & 5.11 & 4.55 & 5.54 & 5.24 & 5.57 & 5.26 & 5.03 \\ 2.68 & 3.67 & 3.10 & 4.10 & 3.79 & 4.12 & 3.81 & 3.59\end{array}$


panel \# 3

Extending PMG to linear gap effects ${ }^{\mathrm{d}}$

- long-run pooled gap effect $=0$

- long- and short-run gap effects $=0$

Nonlinear gap effects PMG model ${ }^{\mathrm{e}}$

- long-run asymmetry: $\phi_{5}+\phi_{6}=0$

- short-run gap effect: $\lambda_{14}^{h}=0$

- nonlinear dynamics: $\lambda_{2 N}^{h}=\lambda_{2 N}$

- joint LR test of the restrictions above

Restricted nonlinear PMG model ${ }^{\mathrm{f}}$

$\lambda_{2 P}^{h}$

$\lambda_{2 P}^{h}+\lambda_{2 N}$

$\phi_{1 P}=\phi_{1}+\phi_{5} \mathrm{~g}$

inflation effect when gap $>0=-\phi_{5}$ h

$$
\phi_{1 N}=\phi_{1}
$$

Testing for the absence of ${ }^{\mathrm{i}}$

- overreaction with gap $>0$

- overreaction with gap $<0$

- overshot revision with gap $>0$

- overshot revision with gap $<0$

Long-run expected inflation bound: ${ }^{1}$

\section{- upper-bound}

- lower-bound

0.2846

0.4961

0.3333

0.1799

0.5006

0.5194

0.3266

0.4949

0.5591

0.4761

0.3274

0.8454

0.7642

0.5435

0.8181

$-0.736$

$-6.31$

$-0.5339$

$-4.48$

6.3676

15.35

$-3.0278$

$-8.49$

3.3399

14.89

0.0918

0.0897

0.2356

0.8687

3.98
2.54

$$
-8.74
$$

$-0.6065$

$-6.19$

$-0.8072$

$-7.08$

$-0.4039$

$-4.08$

6.3676

$15.35 \quad 15.35$

$-3.0278$

$-8.49$

$-3.0278$

$-8.49$

3.3399

14.89

14.89

0.3638

0.3633

0.0065

0.2967

0.0166

0.0212

0.7501

0.3315

4.26

4.62

3.18

\section{$-0.7187$}

$-6.79$

$-0.5162$

$-4.80$

6.3676

15.35

$-3.0278$

$-8.49$

3.3399

14.89

0.0039

0.0051

0.9515

0.1786

-0.5128
-5.42

-0.9533
-7.83

$-0.5497$

$-0.3966$

$-0.9369$

$-9.22$

$-0.5824$

$-0.3103 \quad-0.7507$

$-3.18$

$-6.19$

$-0.3472$

$-3.55$

6.3676

15.35

$-0.1940$

$-0.7344$

$-7.14$

6.3676

6.3676

6.3676
15.35

$-3.0278$

$-8.49$

3.3399

14.89

3.3399

14.89

3.3399

14.89

(0.001

0.0082

0.3507

0.3723

0.0001

0.3161

0.8214

0.4005

0.0134

$-5.84$

$-0.3798$

$-3.72$

6.3676

15.35

$-3.0278$

$-8.49$

3.3399

14.89

0.0385

0.0545

0.6069

$\begin{array}{ll}0.3431 & 0.1293 \\ 0.9827 & 0.6482\end{array}$

0.1686

5.51

5.64

5.95

4.51

4.57

3.13

3.07

5.2

5.49 5.49
4.05 
panel \# 4

Extending PMG to linear gap effects ${ }^{\mathrm{d}}$

- long-run pooled gap effect $=0$

0.4348

- long- and short-run gap effects $=0$

Nonlinear gap effects PMG model ${ }^{\mathrm{e}}$

- long-run asymmetry: $\phi_{5}+\phi_{6}=0$

0.6855

0.1200

0.5136

0.5134

0.7048

0.0923

0.5698

- short-run gap effect: $\lambda_{14}^{h}=0$

0.3740

- nonlinear dynamics: $\lambda_{2 N}^{h}=\lambda_{2 N}$

0.2614

- joint LR test of the restrictions above

0.9622

Restricted nonlinear PMG model ${ }^{\mathrm{f}}$

0.7464

$\lambda_{2 P}^{h}$

$\lambda_{2 P}^{h}+\lambda_{2 N}$

$\phi_{1 P}=\phi_{1}+\phi_{5} \mathrm{~g}$

inflation effect when gap $>0=-\phi_{5}$ h

$\phi_{1 N}=\phi_{1}$

Testing for the absence of ${ }^{\mathrm{i}}$

- overreaction with gap $>0$

- overreaction with gap $<0$

- overshot revision with gap $>0$

- overshot revision with gap $<0$

Long-run expected inflation bound: ${ }^{1}$

$-0.8467$

$$
-7.71
$$

$-0.6648$

$$
-6.96
$$

$-0.5927$

$-0.6145$

$-0.9236$

$-0.7973$

$-0.5433$

$-0.3438$

$-0.6619$

$-5.90$

$-8.10$

$-7.56$

$-5.63 \quad-4.24$

$-6.08$

$-4.85$

0.4079

$-0.7387$

$-0.6124$

$-0.3584$

$-0.1590$

6.559

659

0.50

$-5.65$

$-3.66$

$-1.89$

14.2

14.2

6.559

14.2

14.2

6.559

$6.559 \quad 6.559$

$-2.9881$

$-2.9881$

$-2.9881$

$-2.9881$

$-2.9881$

14.2

$-2.9881$

14.2

$-7.46$

$-7.46 \quad-7.46$

$-7.46$

$-7.46$

$-7.46$

$-2.9881$

3.5705

3.5705

3.5705

3.5705

3.5705

3.5705

5705

$-7.46$

14.20

14.20

14.20

3.5705

$\begin{array}{llllllll}0.0000 & 0.0032 & 0.2824 & 0.0033 & 0.2884 & 0.0003 & 0.0665 & 0.0000\end{array}$

$0.0000 \quad 0.0036$

0.2824

0.0000

0.0664

0.6438

0.0916

0.6112

0.2894

0.9426

0.0664

0.0018

0.1043

0.9318

0.1081

0.6491

0.0018

- upper-bound

5.19

5.02

4.76

4.49

6.49

5.92

5.33

4.45

$3.47 \quad 3.22$

2.95

4.94

4.38

3.78

2.91 


\section{${ }^{\left({ }^{a}\right)}$ Group definitions are in Table 4.}

( $\left.{ }^{b}\right)$ Maximum likelihood estimates (below, the corresponding Student-t statistics).

${ }^{c}$ ) When in the first column there is a restriction, p-values under such null hypothesis are reported.

(d) P-values of variable addiction to linear PMG model. Gap is measured as: $\operatorname{gap}_{t}=\frac{E_{t}^{F}\left(\pi_{t+1}\right)-\pi_{t-1}}{s e_{t}^{F}\left(\pi_{t+1}\right)}$

$\left.{ }^{(}\right)$P-values of restrictions to maximum likelihood estimates of the model (note that the Heaviside indicator is $I_{t}=1$ if $\operatorname{gap}_{t-1}<0$ and $I_{t}=0$ if gapt $_{t-1} \geq 0$ ) $\left.\Delta E_{t}^{h}\left(\pi_{t+1}\right)=\lambda_{10}^{h}+\lambda_{11}^{h} \Delta E_{t}^{F}\left(\pi_{t+1}\right)+\lambda_{12}^{h} \Delta \pi_{t}^{P, h}+\lambda_{14}^{h} \Delta g a p_{t}+\left(\lambda_{2 P}^{h}+\lambda_{2 N}^{h} I_{t-1}\right)\left[E_{t-1}^{h}\left(\pi_{t}\right)-\phi_{1} E_{t-1}^{F}\left(\pi_{t}\right)-\left(\phi_{5}+\phi_{6} I_{t-1}\right) g a p_{t-1}\right)\right]+\varepsilon_{t}^{h}$

$\left({ }^{f}\right)$ Maximum likelihood estimates of the model:

$\left.\Delta E_{t}^{h}\left(\pi_{t+1}\right)=\lambda_{10}^{h}+\lambda_{11}^{h} \Delta E_{t}^{F}\left(\pi_{t+1}\right)+\lambda_{12}^{h} \Delta \pi_{t}^{P, h}+\left(\lambda_{2 P}^{h}+\lambda_{2 N} I_{t-1}\right)\left[E_{t-1}^{h}\left(\pi_{t}\right)-\phi_{1} E_{t-1}^{F}\left(\pi_{t}\right)-\phi_{5}\left(1-I_{t-1}\right) g a p_{t-1}\right)\right]+\varepsilon_{t}^{h}$

$\left({ }^{\mathrm{g}}\right)$ Computed under the assumption that the consensus standard deviation is equal to the sample average $(0.22)$.

(') $P$-values of $\mathrm{H}_{0}$ : $\lambda_{11}^{h}=-\lambda_{2}^{h}$, and $\mathrm{H}_{0}$ : $\lambda_{11}^{h} /-\lambda_{2}^{h}=\phi_{1}$ respectively evaluated with both positive and negative gaps estimates; see also Appendix A1.2.

(') Interval estimation of long-run steady state households' inflation expectations. 


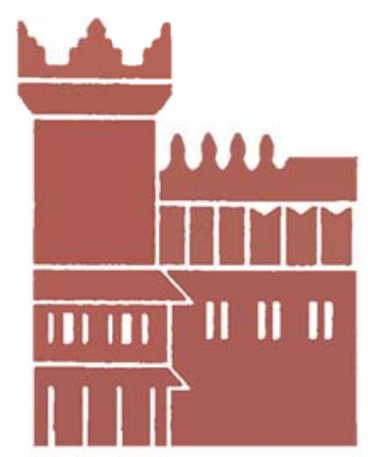

Alma Mater Studiorum - Università di Bologna DEPARTMENT OF ECONOMICS

Strada Maggiore 45

40125 Bologna - Italy

Tel. +39051 2092604

Fax +390512092664

http://www.dse.unibo.it 